\title{
El ÚlTimo RECINTO AMURALLADO DE MADĪNAT IŠBİLIA. ESTADO DE LA CUESTIÓN Y PERSPECTIVAS DE FUTURO
}

\author{
Daniel JimÉnez Maqueda \\ Pedro Pérez Quesada
}

Recibido: 19/01/2015

Revisado: 23/02/2015

RESUMEN

El presente artículo tiene como objetivo actualizar nuestros conocimientos sobre el último recinto amurallado de madīnat Išbīlia, erigido en los siglos VI/XII-VII/XIII. Asimismo, nos proponemos establecer nuevas líneas de investigación sobre el recinto que permitan, algún día, establecer su cronología de forma definitiva.
Aceptado: 26/02/2015

Publicado: 30/05/2015
Palabras Clave

Išbīlia; Muralla; Almorávides; Almohades; Arqueología.
ABstract

This article has as an objective to update or knowledge of the last wall of madinnat Išbìlia, built in $6^{\text {th }} / 12^{\text {th }}-7^{\text {th- }} 13^{\text {th }}$ centuries. Therefore, we'd like to establish new lines of investigation about the wall in order to set its chronology in a definite way.
KEYWORDS

Išbīlia; wall; Almoravids; Almohads; Archaeology.

maqueda@hotmail.es

pedro@geasconsultores.com 
No siempre es poderosa,

Carrero la maldad, ni siempre atina

la envidia ponzoñosa,

y la fuerza sin ley que más se empina

al fin la frente inclina

(Fray Luis de León, Oda XV-a Don Pedro Portocarrero).

\section{UNA DECLARACIÓN DE INTENCIONES.}

La cronología del último recinto amurallado de Sevilla ha sido, y es objeto, de una polémica controversia entre quienes defienden una autoría completamente almohade para el mismo (Valor, 1991; 1995; 2002a, 48; 2002b; 2004, 147 ss.; 2008a, 25 ss.; 2008b, 147; 2009a, 193 ss.; 2014, 252-253; Valor y Ramírez, 1999; 2000; Ramírez y Valor, 1999; Valor y Tabales, 2002; 2005, 196 ss.) y quienes, por el contrario, sostenemos una paternidad compartida entre almorávides y almohades (Torres Balbás, 1952, 413 ss.; 1955, 20; Guerrero Lovillo, 1953, 180; 1972, 35; Collantes de Terán, 1957, 18 ss.; 1977, 105-107; Salem, 1979-1980; Bosch, 1984, 305-309; Valencia, 1986, 156 ss.; Jiménez Martín, 1981, 16-17; 2000, 47 ss.; 2007, 27 ss.; Domínguez, 2003, 295 ss.; 2014, 246-250).

Sin embargo, no es nuestra intención insistir sobre los argumentos que nos han permitido defender que el último recinto amurallado de madīnat Išbìlia fue erigido entre los años 519/1125-1126 y 528/1133-1134, en tiempos del emir almorávide 'Alī ibn Yūsuf (Jiménez Maqueda, 1996a; 1996b; 1998a; 1998b; 1998c; 1999a, 213-215; 1999b, 151-152; 2007, 167 y 170; Jiménez Maqueda y Pérez, 2012, 237).

En esta ocasión nuestro propósito es el de establecer una nítida distinción entre lo que, en la actualidad, son hechos incuestionables, asumibles por cualquier investigador, y lo que, por el momento, no son más que hipótesis enfrentadas sobre la cronología de las murallas de Sevilla1.

$1 \mathrm{El}$ presente artículo no se enmarca en ningún proyecto de investigación ni ha recibido ayuda financiera alguna por parte de ninguna institución pública o privada. Es por ello que resulta especialmente oportuno mostrar nuestro profundo agradecimiento a aquellos que han tenido la amabilidad de proporcionarnos su ayuda.

En primer lugar, queremos hacer mención a los profesores de la Universidad Hispalense Fernando Amores Carredano, del Departamento de Prehistoria y Arqueología de la Facultad de Geografía e Historia, y Miguel Ángel Tabales Rodríguez, del Departamento de Construcciones Arquitectónicas II de la Escuela Universitaria de Arquitectura Técnica. Asimismo, estamos en deuda con José Manuel Rodríguez Hidalgo, de la Delegación Provincial en Sevilla

\section{Algunas Certezas...}

2.1. Lo que las fuentes árabes nos cuentan...o no dicen.

"Son muy escasas las ocasiones en las que las fuentes árabes medievales brindan datos explícitos relativos no solo a la fecha de construcción de una fortaleza o de una muralla urbana, sino también a las técnicas empleadas en ésta. Cuando ocurre, no obstante, no es oro todo lo que brilla, y en la mayoría de los casos en los que sí se brindan tales precisiones, éstas son más engañosas que lo que se podría esperar"

(Acién y Cressier, 2009, 177).

Las noticias que figuran en las diversas fuentes árabes sobre las murallas de madinat Išbīlia, así como la ausencia de las mismas, constituyen un argumento fundamental tanto para quienes defendemos una autoría almorávide como para quienes sostienen una paternidad almohade. En este sentido, como quiera que, en ocasiones, un mismo pasaje es utilizado para defender hipótesis

de la Consejería de Cultura de la Junta de Andalucía, Oscar Ramírez Reina, del Servicio de Planeamiento de la Gerencia Municipal del Ayuntamiento de Sevilla, Inmaculada Carrasco Gómez, del Seminario de Arqueología de la Universidad Pablo de Olavide, Enrique Domínguez Berenjeno y Samuel Márquez Bueno.

Por otra parte, para la confección de la figura 10 debemos agradecer la ayuda de los siguientes investigadores: Luís Campos Paulo, de la Câmara Municipal de Albufeira, Luís Filipe Santos, del Museu Municipal de Faro, Isabel Luzia, de la Câmara Municipal de Loulé, António Rafael Carvalho, Juan Manuel Campos, del Departamento de Historia I de la Universidad de Huelva, Laureano Aguilar, del Museo Arqueológico de Jerez de la Frontera, Tania Bellido, Sergio García-Dils, del Servicio Municipal de Arqueología del Ayuntamiento de Écija, Alberto León, del Área de Arqueología de la Facultad de Filosofía y Letras de la Universidad de Córdoba, Juan Carlos Castillo, de la Facultad de Humanidades de la Universidad de Jaén, José Mayorga, del Taller de Investigaciones Arqueológicas de Málaga, Sophie Gilotte, del CNRS, Manuel Retuerce, Gemma Jurado y el Servicio de Investigación Arqueológica Municipal del Ayuntamiento de Valencia.

Por último, no hubiéramos podido realizar la figura 12 sin la colaboración de numerosos colegas sevillanos que han atendido con infinita paciencia nuestras constantes peticiones de información sobre intervenciones arqueológicas dirigidas por ellos. En esta nómina no pueden faltar Francisco Javier España, Jaime González, Mark Hunt, Álvaro Jiménez, Daniel Lara, Juan Carlos Mejías, Gregorio Mora, Pablo Oliva, Mercedes Ortega, Sergio Pineda, Florentino Pozo, Gilberto Rodríguez, José Antonio Valiente, Miguel Ángel Vargas, Elena Vera y Manuel Vera. 
antagónicas, nos limitaremos a enumerar los autores y sus obras en las que se recogen intervenciones en la cerca sevillana. Asimismo, haremos alusión también a las fuentes árabes en las que no se afirma que los almohades erigieran la muralla de Sevilla.

En primer lugar, hacemos referencia a las fuentes árabes que afirman, expresamente, que durante la dominación almorávide se efectuaron obras en el recinto amurallado sevillano, como sucede con Ibn

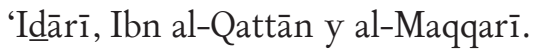

Ibn 'I $\underline{\text { dārī }}$, muerto en 1320, hace alusión en un pasaje de su Bayān al-Mugrib, que todavía redactaba en 1312-1313, a la imposición, en 519/1125-1126, de un impuesto denominado ta'tib, con el que se sufragó la construcción de las murallas de Granada, Córdoba, Almería y Sevilla ${ }^{2}$.

El tremeciano al-Maqqarī, muerto en 1632, narra en su Nafh al-tib cómo el $q \bar{a} d \bar{\imath}$ de Sevilla, Abū Bakr ibn al-'Arabī, construyó, en el año 528/1133-1134, las murallas de la ciudad con piedra, ladrillo y cal, mediante el importe de la venta de las pieles de los corderos ofrecidos en sacrificio, tras un primer $y$ fallido intento debido a la oposición de la población a sufragar su erección (Salem, 1979-1980, 176; Bosch, 1984, 306; Ramírez y Valor, 1999, 171-172; Valor y Ramírez, 1999, 29; 2000, 89).

Del mismo modo, Ibn al-Qattān, que compuso su Nazm al-ŷumān para el califa almohade al-Murtada a mediados del siglo XIII, y del que sólo se conserva el tomo correspondiente a los años 1107 a 1138 (Viguera, 1997, 11-12), atribuye también a Abū Bakr la construcción, en 528/1133-1134, del sector de murallas paralelo al río(Salem, 1979-1980, 176).

En segundo lugar, hay que mencionar las fuentes árabes que muestran una ausencia de noticias en relación a la construcción de la muralla de Sevilla por los almohades, algunas de las cuales, no obstante, hacen referencia a reparaciones o a obras de menor entidad (figuras 1-2). En ellas incluimos las obras de Ibn Sāhib al-Salāt, 'Abd al-Wāhid al-Marrākuš̄i Ibn 'I d̄ārī e Ibn Abī Zar'.

2 "Se encargó de mirar por las murallas de Almería un hombre de ella (...) y se acabó la muralla, según lo exigía de fortaleza y hermosura, con el menor gasto, sin golpe ni cárcel. Se encargó la gente de Córdoba de reparar sus muros según la costumbre antigua, y se ocupó la gente de cada mezquita de levantar lo que le era contiguo, y se terminó la obra sin tumultos ni reclamaciones, y lo mismo la gente de Sevilla, con un término medio, sin prodigalidad ni daño" (Ibn 'Id̄ārīi, 1963, 170-172).
En el Mann bi-l-Imāma de Ibn Sāhib al-Salāt, vivo aún en 1198, no se recoge noticia alguna de que las murallas de Sevilla fueran obra de los almohades, si bien es cierto que sólo se conserva la segunda parte, que abarca los años 1159 a 1173 . En este sentido, se trata de una ausencia fundamental, en la medida en que este autor fue contemporáneo y testigo directo de los hechos que narra y en que, por su cargo en la administración, tuvo acceso a documentos oficiales (Huici, 1969, 7-8; Viguera, 1997, 10). Asimismo, cabría añadir que sí se hace eco de otras construcciones de carácter defensivo en otros puntos de al-Andalus, como Gibraltar o Badajoz (Ibn Sāhib al-Salāt, 1969, 23 y 149), y de la propia Išbīlia almohade, como la reconstrucción, por orden de Abū Ya'qūb, del lienzo del lado del río destruido por la inundación de 564/1168-11693 , las alcazabas exterior e interior en 566/1170-1171 ${ }^{4}$ y la muralla de la explanada de Ibn Jaldūn, de 580/1184 ${ }^{5}$.

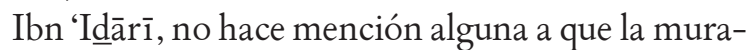
lla sevillana fuese erigida por los almohades. Sin embargo, aunque para el período que nos interesa sigue fielmente el Mann bi-l-Imāma (Huici, 1963, 7-8; $1969,7)$ y que la suya era una obra general sobre la historia del Occidente islámico(Huici, 1953, IX-XI; Viguera, 1997, 12; Ibn 'Id̄āri, 1993, IX), encontramos noticias relativas a otras fortificaciones del resto de al-Andalus, como las de Alcalá de Guadaira, Beja y el Hisn al-Faraŷ, en la actual localidad sevillana de San Juan de Aznalfarache(Huici, 1953, 14, 20, 176 y 177), el Magreb, como las de Marrakech(Huici, 1953, 57-58), y la propia Sevilla, como la alcazaba erigida en el año $544 / 1150^{6}$.

3 "Es el que hizo una capital de Sevilla [Abū Ya'qūb], y el que mandó reconstruir sus murallas por el lado del río, a su costa, después que las derribó la inundación grande, que salió por sus costados y por su región el año 564 [5 octubre 1168 a 24 de septiembre 1169]. Las construyó de piedra y cal, desde ras de tierra hasta la altura que tienen hoy, por mano de sus encargados más fieles" (Ibn Sāhib al-Salāt, 1969, 64).

4 "Se instaló [Abū Ya'qūb] en Sevilla el año 566 [14 septiembre 1170 a 3 septiembre 1171] (...) Labró la alcazaba interior y la alcazaba exterior en las afueras de la puerta de al-Kuhl (...)" (Ibn Sāhib al-Salāt, 1969, 65).

5 “(...) mandó a su gobernador Abū Dāwūd Yalūl b. $\hat{Y}$ aldāsan, que se ocupase durante su ausencia por la campaña, en construir una muralla fuerte en la alcazaba de Sevilla, que pasase desde el principio de su construcción por delante de la explanada de Ibn Jaldūn dentro de Sevilla (...)" (Ibn Sāhib al-Salāt, 1969, 200).

6 ".... "una alcazaba en Sevilla para que a ella se trasladaran los Almohades residentes en [el barrio del Cementerio]al-Ŷabbāna, por las quejas de la gente contra el daño que 


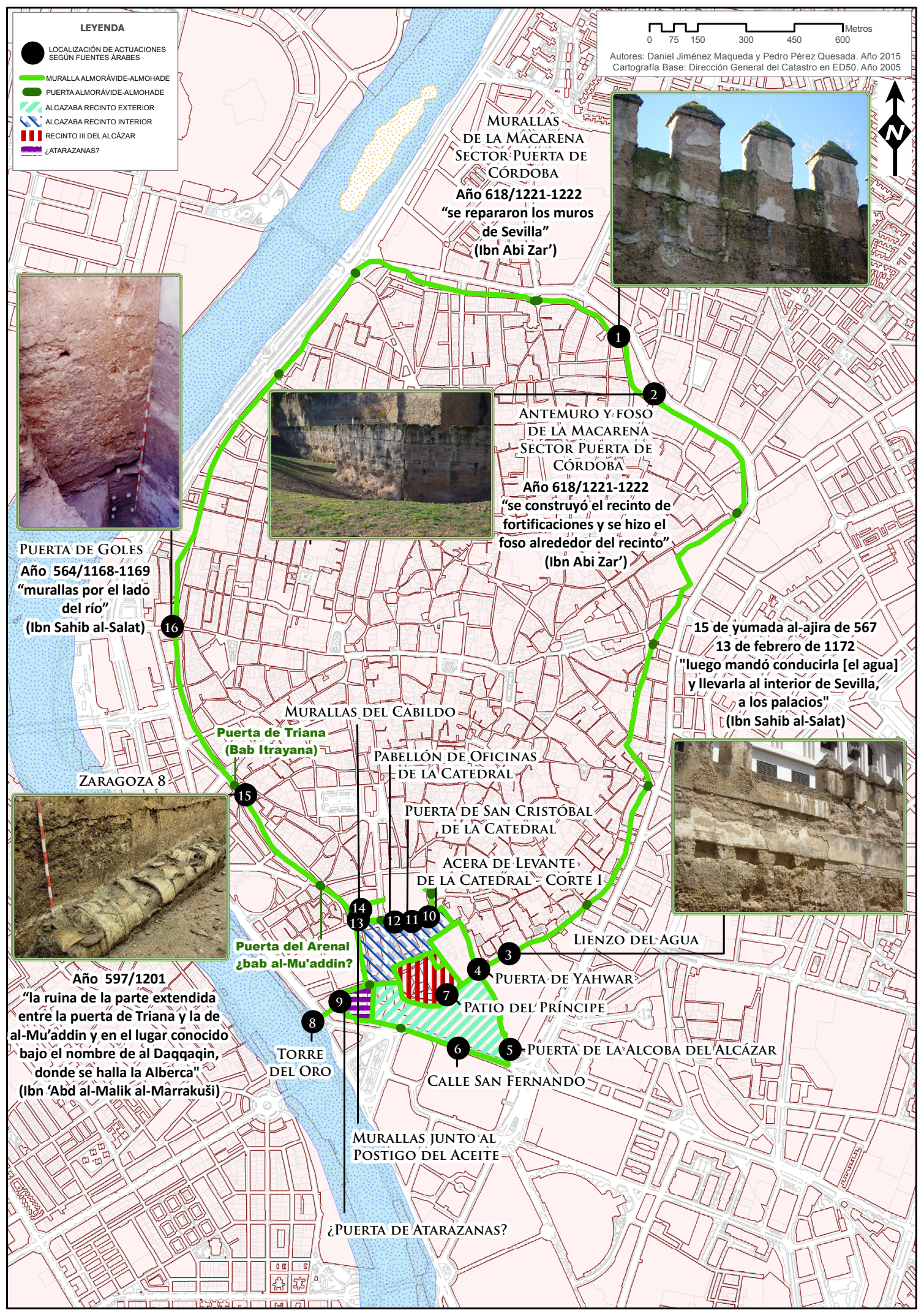

Figura 1. Intervenciones almohades en las murallas de Išbīlia según las fuentes árabes mencionadas en el texto. 


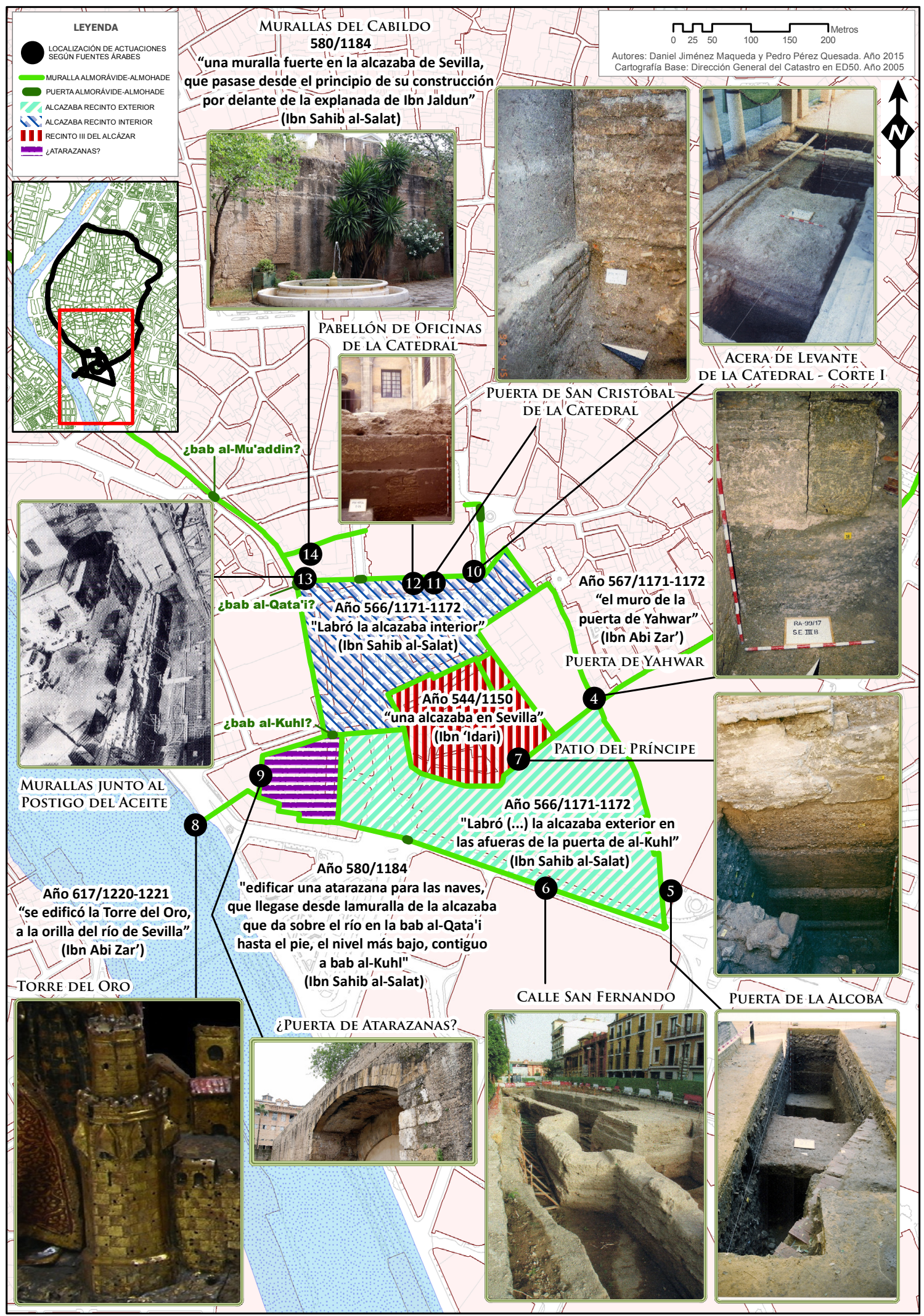

Figura 2. Intervenciones almohades en las murallas de Išbīlia según las fuentes árabes mencionadas en el texto. Sector meridional. 
'Abd al-Wāhid al-Marrākušī en su Kitāb al$m u \hat{y} i b$, redactado, a petición de un personaje deseoso de conocer la historia del Occidente musulmán, tras emigrar a Oriente en 1217 (Huici, 1955, XI-XII; Viguera, 1997, 10-11), tampoco conserva noticia alguna de que fuesen los almohades quienes edificaron las murallas de Išbìlia. No obstante, la información que proporciona debe ser tomada con cautela debido a su poca preparación como historiador y a su falta de obras de consulta (Huici, 1955, XXIII). No obstante, ello no le impide relatar las obras de Gibraltar y del Hisn al-Faraŷ (Huici, 1955, 173-174 y 243-244).

Ibn 'Abd al-Malik al-Marrākušī afirma que, en la tarde del martes 19 de $\hat{y} u m a \overline{d a}$ II del año 597/26 de marzo de 1201, tuvo lugar una inundación, que volvió a derribar sendos lienzos de la muralla por el lado del río, entre la Puerta de Triana y la Puerta del Almuédano ${ }^{7}$.

Por último, el Rawd al-qirtās del fesí Ibn Abī Zar', redactado en el primer cuarto del siglo XIV para el sultán benimerín Abū Sa'īd 'Utmān(Ibn Abī Zar', 1964, 15; Viguera, 1997, 13). En él las intervenciones almohades en las murallas de la ciudad se fechan en 567/1171-1172, cuando se erigió "el muro de la puerta de Ŷahwar"(Ibn Abī Zar', 1964, 417), en 617/1220-1221, cuando "se edificó la Torre del Oro, a la orilla del río de Sevilla”, y en 618/1221-1222, cuando "se repararon los muros de Sevilla, se construyó el recinto de fortificaciones y se hizo el foso alrededor del recinto" (Ibn Abī Zar’, 1964, 523). No obstante, son conocidas las carencias que afectan a esta crónica, las cuales la hacen poco fiable para los períodos almorávide y almohade (Huici, 1964, 17 y 20), aunque en similares términos se expresa la obra al-Dajīra al-Saniyya (Valor y Ramírez, 1999, 35 y $38 ; 2002,92$ ).

les causaban; decidido lo cual, determinaron un lugar -el mismo en el que se halla-, sacando a sus habitantes de sus casas (...)" (Viguera, 1998, 19-20; 1999, 20).

7 “....) la ruina de la parte extendida entre la puerta de Triana y la de al-Mu'addin y en el lugar conocido bajo el nombre de al-Daqqāqin, donde se halla la Alberca; la fuerza de la riada derribó casi $40 \mathrm{Ba}^{\prime}(. .$.$) "(Salem, 1979-1980, 180).$ Para la localización de la Puerta de Triana (Jiménez Maqueda, 1999a, 149). En cuanto al emplazamiento de la bāb al-Mu'adin, la mayor parte de la historiografía sevillana la identifica con la Puerta de Goles (Valencia, 1988, 553), con la excepción de Alfonso Jiménez, que lo hace con la del Arenal, en virtud de la mención a "la Alberca", resto del paleocauce del Guadalquivir que en época moderna se conocerá como la Laguna de la Pajería (Jiménez Martín, 2000, 59).
2.2. El recinto amurallado de Sevilla consta de dos fases.

"Vese por muchas partes deste muro, añadido, y sobrepuesto con tanta unión y fortaleza de la misma materia, que para advertirlo, es necesario mirarlo con atención" (Caro, 1634, folio 20, columna 1).

El recinto amurallado de Sevilla consta de dos fa$\operatorname{ses}^{8}$, resueltas a base de tapias de hormigón de cal. En ellas el análisis de sus propiedades físicas y tipológicas pone de manifiesto grandes similitudes en la composición y ejecución de las fábricas de ambas (Martín et al., 2008, 86).

Sin embargo, el análisis tipológico de la más antigua revela que su primitivo aspecto se caracterizaría por ser simple y bajo, sin decoración alguna y con torres con terraza a la altura del adarve.

En cuanto a la más reciente, consistente en recrecer la cerca en uno o dos cajones y su correspondiente parapeto y merlatura ${ }^{9}$ (figura 3 ), muestra la presencia de dispositivos poliorcéticos típicamente almohades, tales como torres poligonales, antemuro, torres que presentan cámaras abovedadas a la altura del adarve, corachas y una tipología de acceso caracterizada por la utilización de antemuro y torres

8 Se ha señalado la existencia de sendas fases constructivas norteafricanas en diversas fortificaciones de al-Andalus, las cuales presentan características similares a las sevillanas. Así, en la primera de las fases de la cerca de Jerez de la Frontera se alude a torres con terraza a la altura del adarve, mientras que en la segunda se procedió a erigir sobre las mismas cámaras abovedadas (Aguilar, 2000, 105-106; Torremocha, 2004, 113; González, 2006, 89-90). En cuanto a la de Silves, a la primera corresponderían la fase más antigua de la Puerta de la Medina, consistente en un vano flanqueado por dos torres rectangulares, así como otras cinco torres rectangulares de poco saliente (Pavón, 1993, 65; Gomes, 2002, 333; 2003, 142; 2006, 26 y 28). Por último, en la de Belalcázar se documenta una primera fase caracterizada por torres de escasas dimensiones y un zócalo de mampostería y alzado de tabiya (León, 2003, 177-183), mientras que en la segunda se procedió a la reconstrucción y refuerzo de algunas torres y a la reforma y recrecido de los lienzos mediante un aparejo muy similar, aunque con una mayor calidad de los materiales constructivos (León, 2003, 186-190).

9 Este recrecimiento se ha documentado en la murallas de la Macarena (Campos et al., 1987, 354; Campos y Moreno, 1988, 198; Pozo, 2008, 165-166), en los Jardines del Valle (Moreno et al., 1987, 290), en María Auxiliadora 37 (Pozo, 2003, 1115-1116), en María Auxiliadora 39 (Herce, 1996, 14), en Sol 128 y 130-134 (Herce y Franco, 1997, 50), en Sol 122 (Alba y Tabales, 2008), en la Puerta del Osario, en Menéndez y Pelayo 43-45 (Tabales, 2002a, 724, 725, 730 y 731), en el Lienzo del Agua (Tabales, 2002b, 114) y en la Puerta Real (Ramírez y Vargas, 1995, 87-88). 


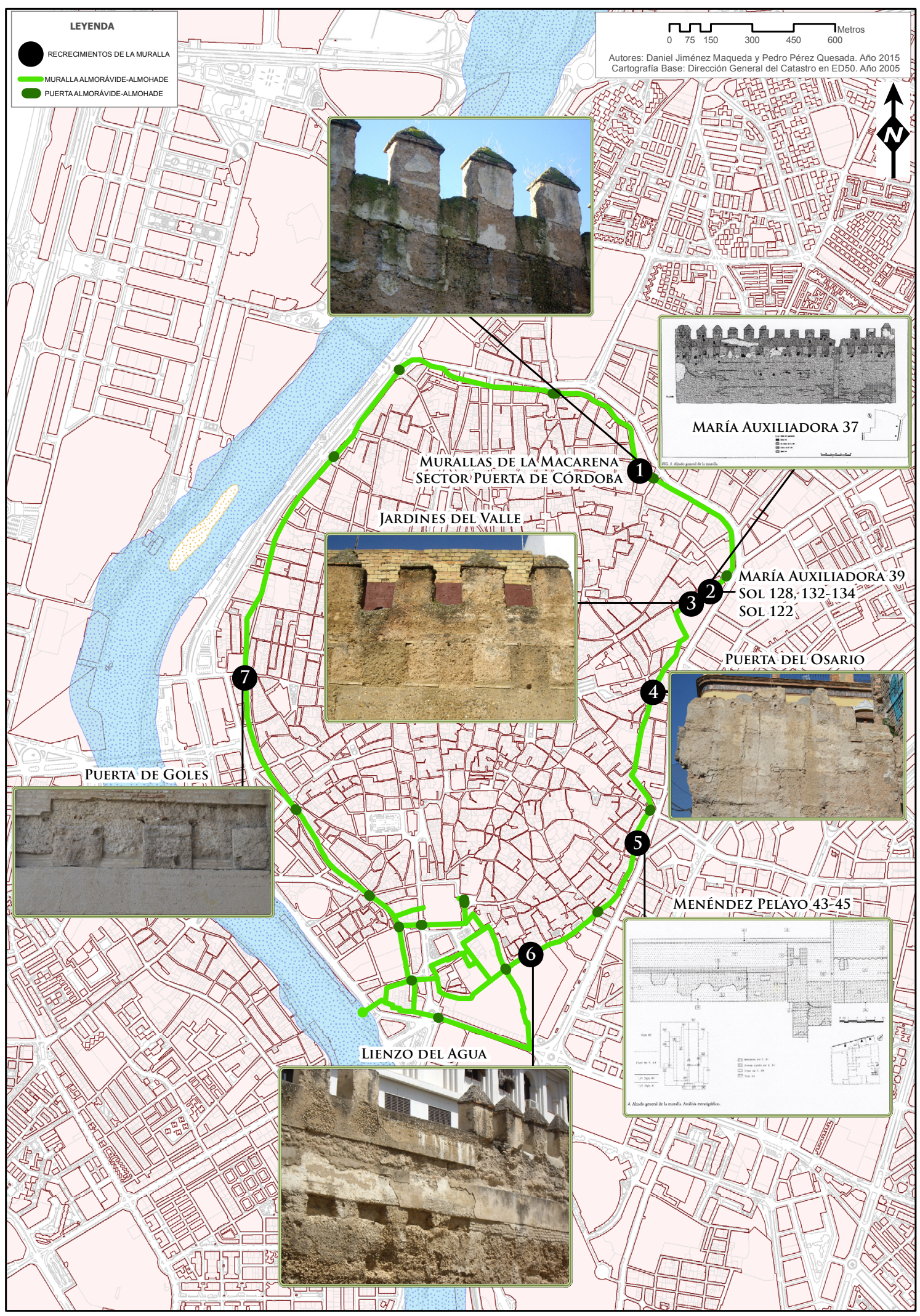

Fugura 3. Puntos del recinto en los que se ha documentado el recrecimiento de la muralla. 


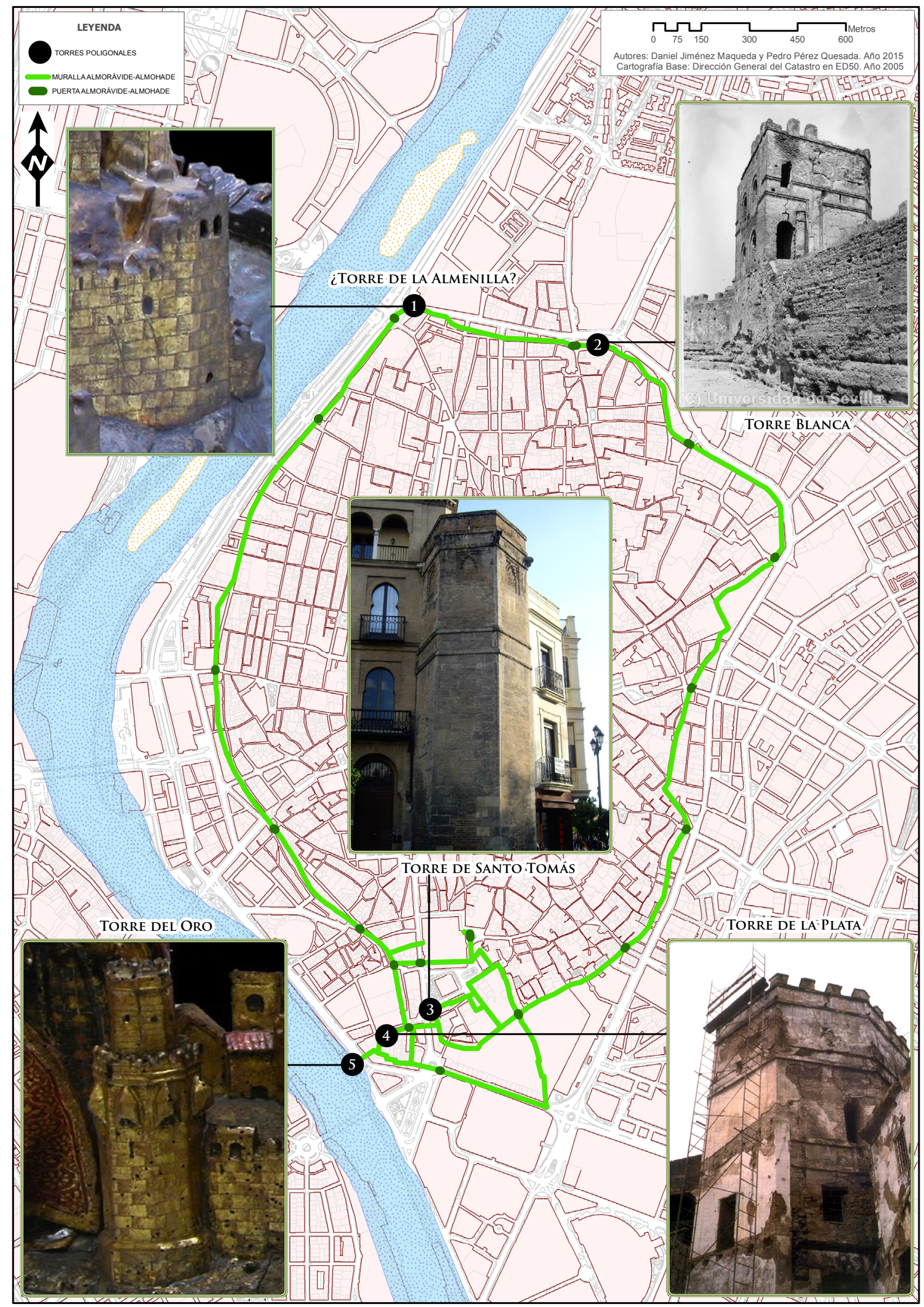

Figura 4. Dispositivos poliorcéticos almohades en la muralla del siglo XII: torres poligonales. 
que flanquean el vano de la muralla, unidos entre sí por puentes laterales.

En relación a las torres poligonales (figura 4), en las fortificaciones de Sevilla contamos con las torres del Oro(Torres Balbás, 1934a; 1934b; Valor, 1991, 251 ss.; 2002b, 323-324; Gómez, 2008; Amores, 2007; 2010; Domínguez y Amores, 2009), Blanca (Valor, 1991, 157 y 162-165; 2002b, 323), de la Almenilla, en el ángulo noroccidental del recinto ${ }^{10}$, de la Plata (Torres Balbás, 1934a; Valor, 1991, 240 ss.; 1993, 386; 2002b, 322-323; Valor y Casquete, 1991) y de Santo Tomás(Valor, 1991, 199), si bien para las dos últimas se ha sostenido una cronología cristiana (Domínguez, 2008, 243-244).

En lo que se refiere al antemuro, no cabe la menor duda de que en el recinto sevillano es posterior a la muralla, tal y como han documentado diversas intervenciones arqueológicas en los últimos años (figura 5). En este sentido, destaca la dirigida por Agustina Quirós y Fernando Amores en las Reales Atarazanas, en la que se excavó una estancia adosada a la muralla que había sido cortada por el antemuro (Quirós, 1999, 191; Amores y Quirós, 1999, 44-45).

Las cámaras abovedadas a la altura del adarve en Sevilla se documentan en algunas de las torres del recrecimiento de la cerca urbana (figura 6) (Collantes de Terán, 1977, 105; Valor, 1991, 129, 132-135, 154-156, $158-160,179,180,199,209$ y $214 ; 2008$ a, 54-55; 2009a, 201-202; Pozo, 2008, 166), así como en las de diversos recintos del Alcázar para los que se sostiene una datación almohade (Valor, 1991, 73, 97, 98, 116, 219, 220, 238, 239 y 270; 1993, 385-386; Tabales, 2002b, 99, 110 y 122; Mora, 2013, tomo 1, 62, 63 y 69).

Por su parte, el empleo de las corachas en la cerca sevillana (figura 6) hay que retrasarlo hasta 617/12201221, cuando se edificó la Torre del Oro, a la que daba acceso una que partía desde el Alcázar(Amores et al., 1987). A esta habría que añadir la que unía la torre de la Almenilla con el ángulo noroccidental del recinto y constituía el cierre septentrional del Arenal(Jiménez Maqueda, 1999a, 192-193; Domínguez, 2008, 238).

10 La primera mención a la misma figura en un documento de los Papeles del Mayordomazgo, fechado en 1386, en el que se afirma: “(...) pasado el alcaçar de la dicha puerta de macarena, la torre del almenilla" (Collantes de Terán, 1968, 53, doc. 33), mientras que Luis de Peraza se refiere a ella, a comienzos del segundo tercio del siglo XVI, en estos términos: “(...) la Almenilla, que es una torre junto a Guadalquivir (...), que está poco delante de la Puerta de Macarena" (Peraza, 1979, 86; 1997, tomo II, 354). Sin embargo, no tenemos la certeza de que se trate de una torre poligonal.
Asimismo, los almohades dotaron a las puertas del primitivo recinto de una tipología de acceso similar a la Puerta de la Medina o de Loulé de Silves (Correia, 1987, 508; Gomes y Gomes, 1992, 290-291; Gomes, 2002, 333-334; 2006, 12 y 26; Pavón, 1993, 56; 1999, 493), la del Repouso de Faro (Pavón, 1993, 75-77; 1999, 450), ambas en el Algarve portugués, y la representación de la granadina de Elvira en la Batalla de Higueruela de El Escorial (Pavón, 1993, 77-79; 1999, 453-454). En todas ellas, encontramos referencias a antemuros que protegen la puerta, torres que pueden flanquear tanto el vano de la muralla como el del antemuro y puentes laterales, que enlazan torres y antemuro. En el caso sevillano, son tres las puertas sobre las que disponemos de datos (figura 6): la Puerta de la Macarena (Jiménez Maqueda, 1996b), la puerta de la alcazaba exterior, denominada desde principios del siglo XV de Jerez ${ }^{11}$ (Collantes de Terán, 1972, 4950, doc. 107), y la Puerta de Córdoba ${ }^{12}$.

Por último, en la segunda fase del recinto sevillano están presentes otros elementos característicos de las fortificaciones de los Unitarios (figura 7), como merlones rematados por albardillas piramidales (Valor, 1991; 1993, 200; 2009a, 53-54; Graciani, 2008, 54), sendos rebajes curvos en la superficie de parapeto entre los merlones de la muralla (Collantes de Terán, 1977, 105; Valor, 1991), presentes también en el antemuro (Valor, 1991; Pozo, 2008, 167) y el Alcázar (Valor, 1991, 239), y, sobre todo, un falso despiece a base de encintados de mortero de cal horizontales y verticales ${ }^{13}$ (Valor, 1991, 51-52; 2009a,

11 Ambas figuran en sendas maquetas del Retablo Mayor de la Catedral, en las que se representan la ciudad vista desde el norte y desde el sur a comienzos del siglo XVI (Sancho, 1975, 1; Cabra y Loredo, 1988, 43; Morón, 1998), mientras que disponemos de una precisa descripción de la Puerta de la Macarena a comienzos del segundo tercio del siglo XVI, obra de Luis de Peraza (Peraza, 1979, 93; 1997; tomo II, 358-359).

12 Según la intervención arqueológica que se llevó a cabo en ella, en época tardo-almohade se procedió a la modificación del diseño de la misma, para lo que se procedió a la erección de dos muros adosados a la muralla y la torre, que estructuran un habitáculo interior de 3,70×2,60 metros. En cuanto al antemuro, se configura con gran complejidad a través de, al menos, dos recintos intermedios, probablemente delimitados por sendos tramos de antemuro, que unirían con la envolvente general (Pozo, 2008, 167-168).

$13 \mathrm{Su}$ finalidad sería tectónica frente a los agentes erosivos, cuando discurren sobre la línea de las cabezas seccionadas de las agujas del encofrado o sobre una junta vertical de obra, decorativa y propagandística. En este sentido, hay quienes defienden que su utilización constituye 
198-199) y el uso de verdugadas o marlotas de ladrillo como elemento decorativo en la parte de las torres que corresponde a la segunda fase (Valor, 1991, 153, $154,156,162,181,197,209,210$ y 214; 2002b, 322; 2004, 152; 2008a, 52-53; 2009a, 199-200; Graciani, 2008, 54; Pozo, 2008, 166) y en las de diversos recintos del Alcázar para los que se sostiene una datación almohade (Valor, 1991, 73, 76, 97, 99, 238 y 239; Tabales, 2002b, 115-119); en la mayoría de los casos, se disponen a la altura de las almenas y a la del pavimento de la terraza o de la cámara(Valor, 1991).

\subsection{La cerámica invisible o por qué la ar-} queología no puede datar la primera fase de la muralla de Sevilla.

“(...) no es posible o al menos científicamente no puede definirse todavía un horizonte claro cerámico entre lo almorávide de los años 20/30 del siglo XII y lo almohade de 1172 (Tabales, 2002b, 201) ${ }^{14}$.

La de la arqueología constituye una de las más importantes contribuciones al estudio de la muralla sevillana en los últimos treinta años, pues hasta mediados de la década de los ochenta había sido objeto de la atención únicamente de arquitectos, arabistas e historiadores del arte. Esta anómala situación, cuya explicación radicaría fundamentalmente en una tradición arqueológica interesada tan solo en la Prehistoria y la Antigüedad Clásica, se vería modificada radicalmente a partir de 1985 . Se inició entonces la aplicación de la metodología arqueológica a los restos del recinto sevillano, el primero de los cuales sería la coracha de la Torre del Oro. En este cambio de actitud desempeñarían un papel fundamental la Delegación Provincial de la Consejería de Cultura de la Junta de Andalucía y, sobre todo, la Gerencia Municipal de Urbanismo del Ayuntamiento de Sevilla.

Sin embargo, la práctica totalidad de las intervenciones arqueológicas que se han llevado a cabo en el recinto sevillano no han alcanzado los depósitos correspondientes a su cimentación ${ }^{15}$, debido a

uno de los componentes del lenguaje formal de las autoridades almohades en las fortificaciones andalusíes (Márquez y Gurriarán, 2008, 117-121 y 133-134; Menéndez et al., 1998; Azuar, 2004, 68-69; 2005, 124-130; Azuar et al., 1996; Azuar y Ferreira, 2014, 403-405 y 411-412).

14 En términos similares se expresa Alberto León (2004, 316-317).

15 Una relación de dichas intervenciones incluye las de Muro de los Navarros 24 (Mejías et al., 2001), la Casa de la Moneda (Campos et al., 1987a; 1987b; Romo y Ortega, 2005; López, 2007; Mora, 2013); Adriano 12 (Romo y Vargas, 1999), Valdés Leal 23 (Viñuales, 1999), Fray Diego de las dificultades técnicas que supone hacerlo por la presencia en el subsuelo sevillano de una lámina de agua. Asimismo, en los contados casos en los que se ha excavado la zanja de cimentación de la muralla la arqueología no se encuentra en condiciones de diferenciar conjuntos cerámicos almohades de la década de 1150 de conjuntos cerámicos almorávides de los años 20 y 30 del siglo VII/XII. A este dato cabría añadir el que no se publiquen las cerámicas sobre las que se fundamentan las dataciones propuestas. De este modo, la aportación de la arqueología a la cuestión de la cronología del recinto amurallado sevillano no es, a día de hoy, concluyente. A pesar de todo, realizaremos un breve análisis de las escasas intervenciones que proporcionan algún dato sobre la fecha de erección del recinto sevillano (figura 8).

Murallas de la Macarena: dirigida por Juan M. Campos en 1985, el dato más significativo de la intervención lo constituiría la supuesta confirmación arqueológica de las diferencias cronológicas establecidas por El Sayed entre la muralla y el antemuro. De este modo, los materiales presentes en la zanja de cimentación de la muralla no sobrepasarían un límite cronológico de mediados del siglo XII, apoyando la tesis de una autoría almorávide. Por su parte, los materiales presentes en la del antemuro sí que sobrepasarían el límite cronológico de mediados del siglo XII, aunque sin ir más allá de la primera mitad del XIII, certificando así una cronología almohade (Campos et al., 1987, 354-355; Campos y Moreno, 1988, 203-204). Sin embargo, el hecho de que estos materiales nunca se hayan publicado cuestiona con severidad la validez de los resultados (Valor, 2008a, 45). A pesar de ello sirvieron de orientación en numerosas intervenciones, tales como las de los Jardines del Valle (Moreno et al., 1987, 290), Marqués de Paradas 29-35(Lorenzo et al., 1987, 306) y Tintes 5-7-9 (Escudero et al., 1990, 600).

En cuanto a la efectuada bajo la dirección de Florentino Pozo en las murallas del sector de la Puerta de Córdoba, a lo largo de 2007 y 2008, el resultado más significativo lo constituye la imposibilidad de

Deza 3 y 5 (Fernández y Rodríguez, 2003); Patio de San Laureano (Carrasco et al., 2013), Goles 19 (Vera, 2008), Goles 39 (Villa et al., 2010), Torneo 48-49 (Pozo, 2001b), Torneo 47 (Pozo, 2001a), Juán de Rabadán 58 esquina calles Torneo y Eduardo Cano (Ormad y Pecero, 1997), Torneo 40-41 (Pozo, 2003a), Torneo 39 esquina Narciso Bonaplata (Vargas y Romo, 2001), Torneo esquina Lumbreras (Jofre y Rodríguez, 2005), Torneo 26 (Amores, 1993), Torneo 23 (Peláez y Gómez, 1991) y Resolana 41 (Chisvert, 1994). 


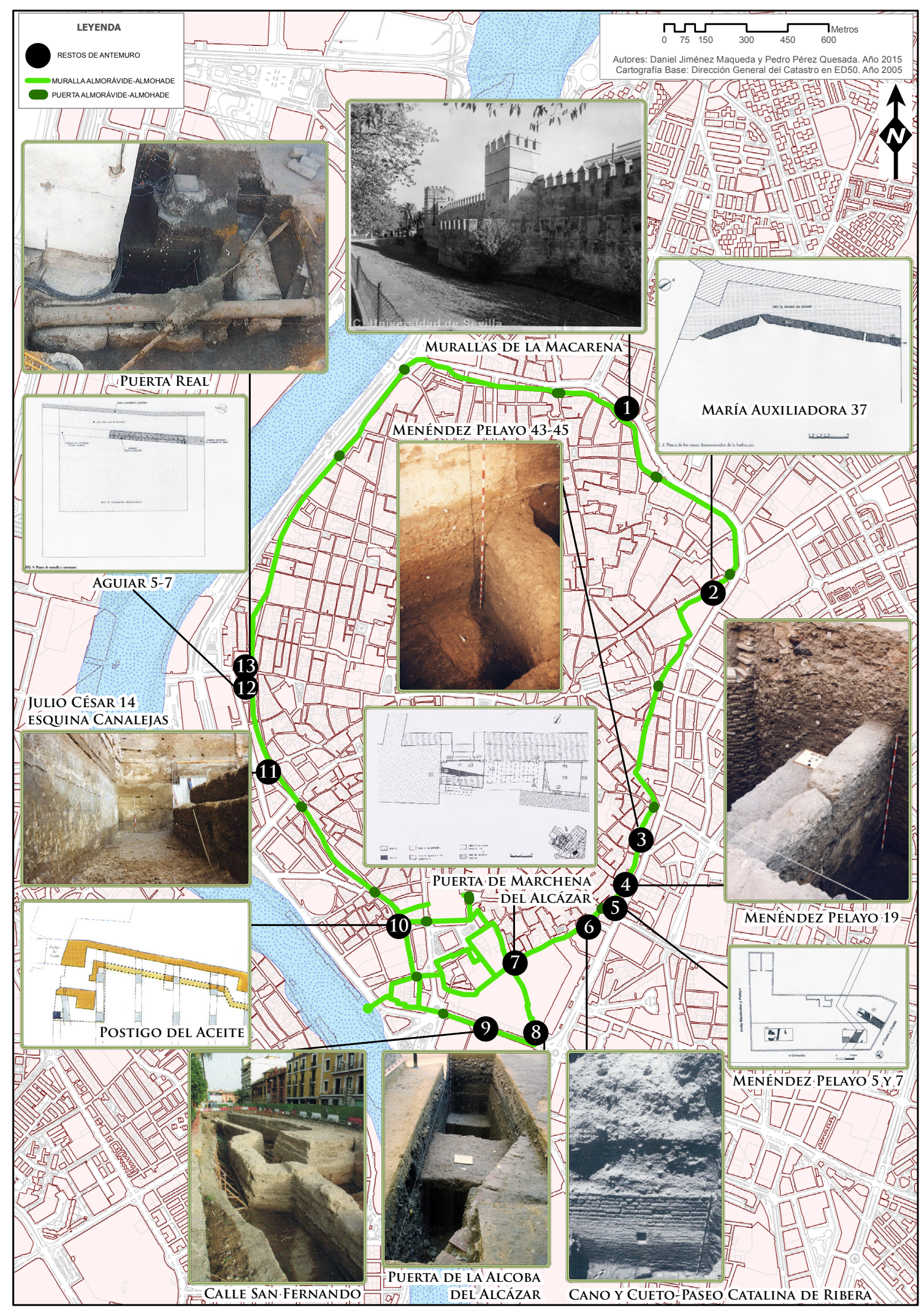

Figura 5. Dispositivos poliorcéticos almohades en la muralla del siglo XII: antemuro. 


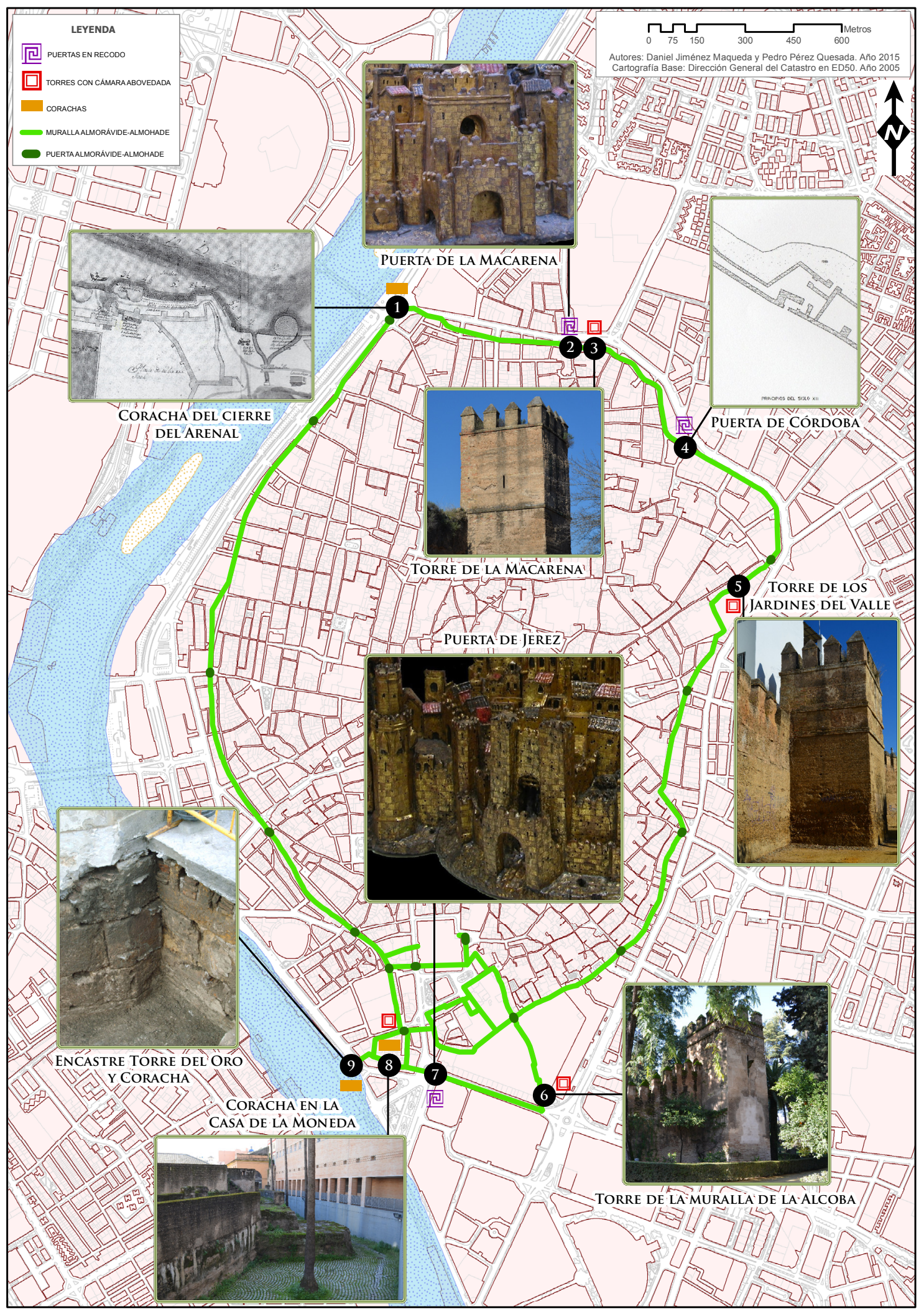

Figura 6. Dispositivos poliorcéticos almohades en la muralla del siglo XII: puertas, torres con cámara abovedada y corachas. 


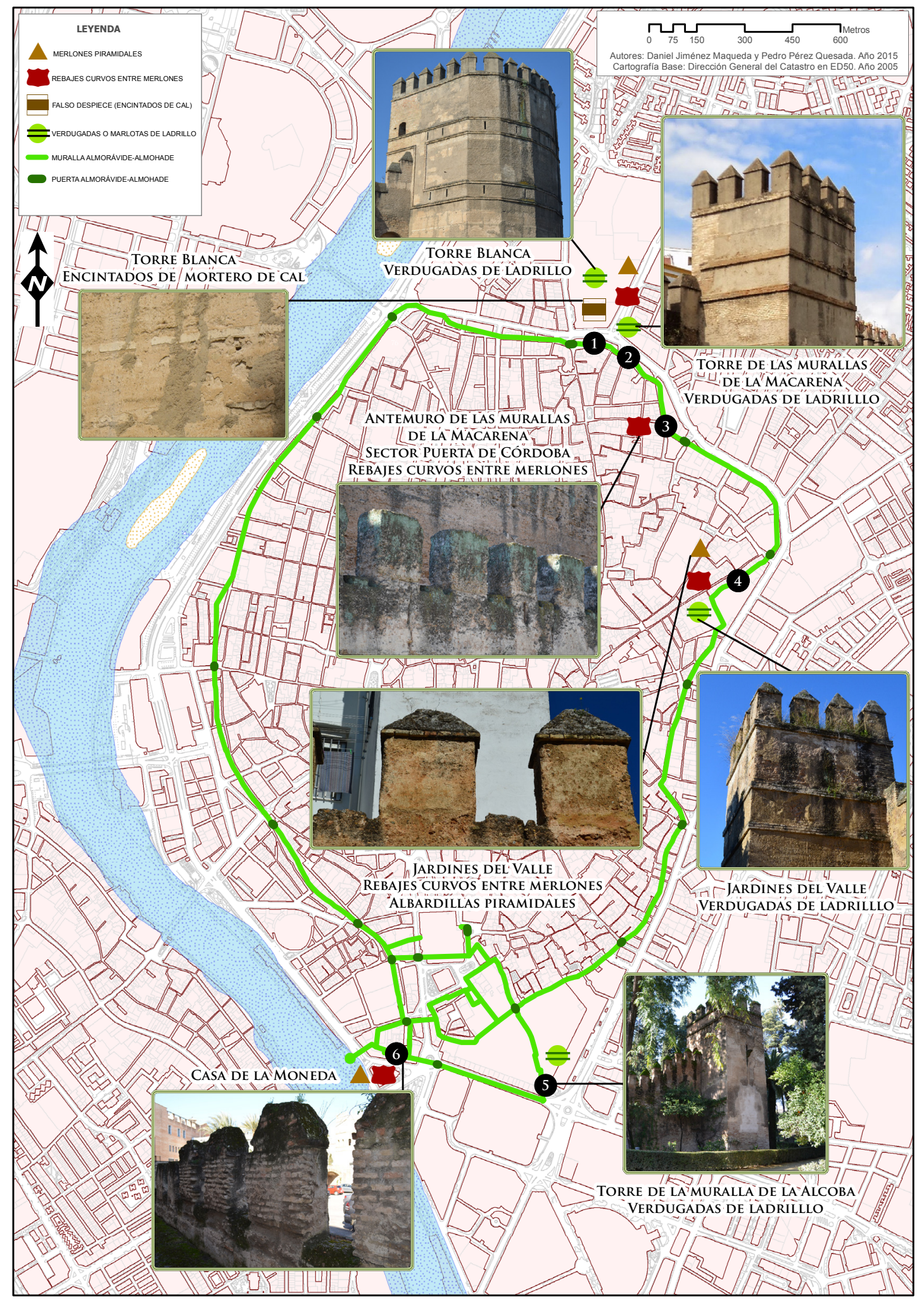

Figura 7. Otros elementos característicos de las fortificaciones almohades en la muralla del siglo XII: merlones rematados con albandillas piramidales, sendos rebajes curvos en la superficie de parapeto entre los merlones, falso despiece a base de encintados de mortero de cal verticales y horizontales y verdugadas o marlotas de ladrillo en el recrecido de las torres. 




Figura 8. Relación de las intervenciones arqueológicas efectuadas en el recinto amurallado mencionadas en el texto. 
datar de forma precisa la construcción de la muralla debido a la escasez del registro cerámico. Así, en virtud del recuperado en los cortes 4 y 5 habría que fechar la misma en el siglo XI, mientras que en el caso del corte 6 la datación correspondería al siglo X (Pozo, 2008, 162).

Calle Cano y Cueto-Paseo Catalina de Ribera: bajo la dirección de Ana Romo, a lo largo de 1996 y 1997 se documentaron 33 metros lineales del antemuro que describía un doble quiebro de $90^{\circ}$. Aunque su zanja de cimentación no se agotó en su totalidad, sus excavadores le asignaron una cronología de la primera mitad del siglo XIII (Romo, 2001). No obstante, los materiales en los que se fundamenta dicha cronología nunca se han publicado.

Sondeo SE-III. Puerta de Marchena del Alcázar: bajo la dirección de Miguel Ángel Tabales en 1999, hasta el momento constituye la única intervención en la que se han documentado sendos recintos amurallados superpuestos (figura 9). Así, el primer amurallamiento se incrusta en la Torre del Agua, consistente en un muro encofrado de tapial de cascote y cal de tonalidad grisácea. Su excavador le asigna una cronología almorávide, a pesar de que los materiales cerámicos a él asociadosadolecen de cierta indefinición, que permitirían sostener también una cronología taif ${ }^{16}$. Un segundo amurallamiento, erigido sobre el anterior una vez que éste fue destruido y que es el visible en alzado en la actualidad, consistente en cajones de tapial con grava de tamaño medio y color anaranjado. Su excavador sostiene una datación almohade anterior a 1172 en base al material cerámico presente en sus niveles asociados, al que define como plenamente almohade ${ }^{17}$.

16 Sin embargo, el análisis minucioso de la secuencia estratigráfica del sondeo SE-III. Puerta de Marchena pone de manifiesto diversas contradicciones e incoherencias en la cronología que sus excavadores asignan a las diferentes unidades estratigráficas documentadas. Así, en el sondeo SE.IIIA. Liza de muralla del Agua, la UEH 739, a la que se define como el paquete de relleno más antiguo del corte, es datada a mediados del siglo XII, extremo incompatible con la circunstancia de que la UEV 741, identificada con el lienzo amurallado más antiguo, se feche a inicios del siglo XII. (Tabales, 2002b, 186). En cuanto al sondeo SE.III-B. Puerta del Agua, la unidad 808, que constituye la clave para fechar la UEV 741, se define como un relleno escaso cuyo material cerámico se fecha en el siglo XI, mientras que, como ya hemos señalado, la UEV 741 es datada por sus excavadores a comienzos del siglo XII (Tabales, 2002b, 197).

17 En el sondeo SE.III-A resulta igualmente contradictorio que a la UEH 738, a la que se define como el relleno de cimentación de la UEV 18, identificada con el lienzo de

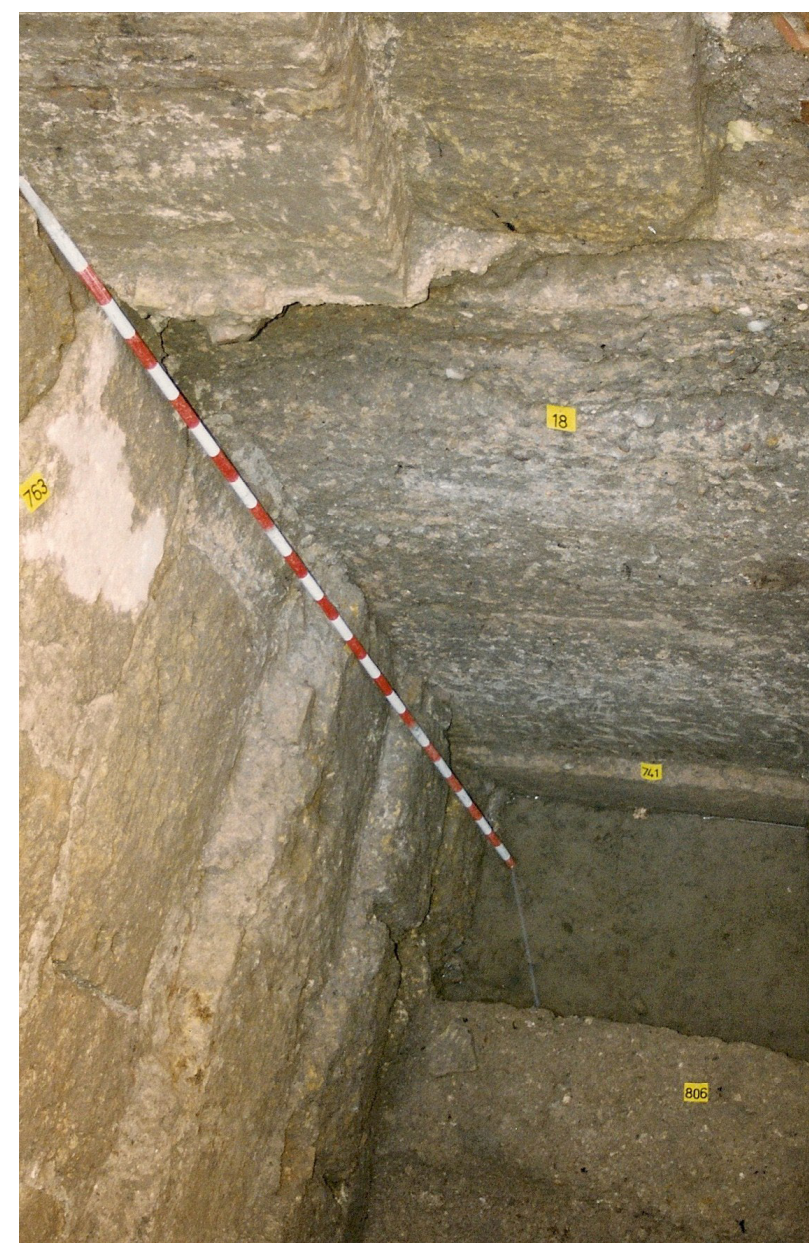

Figura 9. Superposición de los lienzos amurallados UE 741 y UE 18, documentados en el sondeo SE.III de la Puerta de Marchena del Alcázar de Sevilla (fotografía cortesía de Miguel Ángel Tabales). Se trata de un punto clave en el recinto sevillano, en la medida en que, hasta el momento, es el único en el que se han documentado dos lienzos superpuestos, circunstancia que corrobora la hipótesis del doctor Tahiri.

Sondeo SE-V. Sector de la Puerta de la Alcoba del Alcázar: bajo la dirección de Miguel Ángel

muralla más reciente, se le asigne por parte de sus excavadores una cronología de mediados del siglo XII, cuando el $87^{\prime} 85 \%$ de sus fragmentos cerámicos se fechan en los siglos XII-XIII. (Tabales, 2002b, 186). Por su parte, en el sondeo SE.III-B la clave para fechar la UEV 18 la constituyen las unidades 801 y 803, esta última identificada como su posible zanja de cimentación. En este sentido, pese a que sus excavadores atribuyen una cronología almohade a la UEV 18, el material cerámico de la UEH 803 es fechado en su totalidad por sus excavadores en el siglo XI, mientras que el de la UEH 801 se data en la primera mitad del siglo XII, a pesar de que se describe a sus piezas como de poco valor cualitativo y cuantitativo (Ibídem, 2002b, 196-197). 


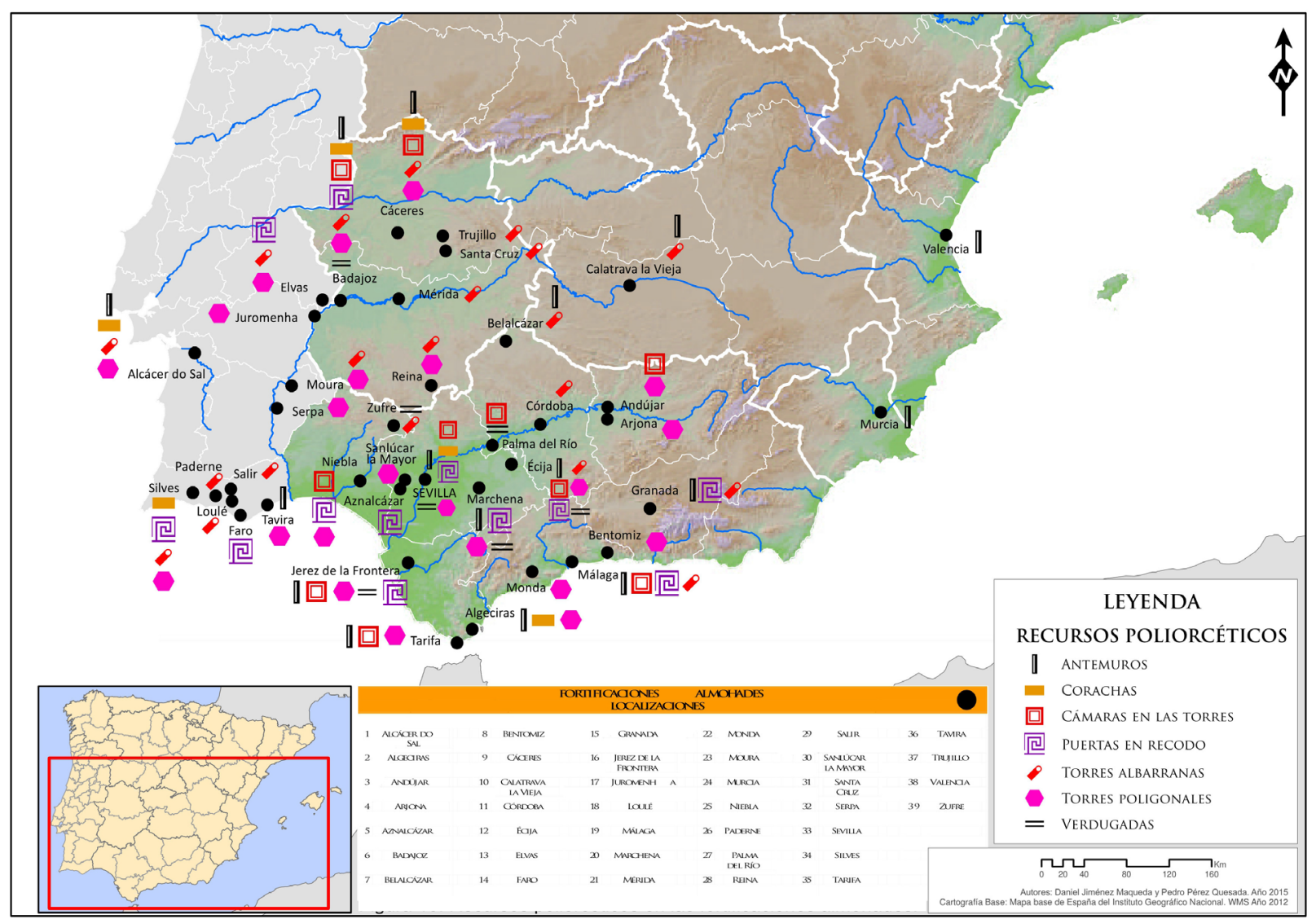

Figura 10. Recursos poliorcéticos en las fortificaciones almohades.

Tabales en 1999, se documentaron la cimentación de la muralla de la alcazaba exterior y su correspondiente antemuro (Tabales, 2002b, 218 ss.; 2002c, 228-230). La primera consistiría en una zanja de un codo de anchura rellena con tejas y abundante cerámica, que permite fechar el lienzo de muralla a fines del siglo XII. Por su parte, la zanja de cimentación del antemuro, con una situación estratigráfica mucho más baja que la muralla y de una anchura inferior al codo, se rellena con arenas fluviales y material cerámico almohade tardío.

Calle San Fernando: bajo la dirección de Mark Hunt en 2004, en el transcurso de la las obras de la Línea 1 del Metro se documentaron la muralla de la alcazaba exterior con sendas torres y el antemuro (Hunt et al., 2010, 4495-4499). Así, en el corte 7 se excavó la zanja de cimentación de la muralla y una torre, rellena con tierra con cascotes, cal y ripios y que permite fechar ambas estructuras en el tercer cuarto del siglo XII. Por el contrario, no se pudo definir la cimentación del antemuro en su totalidad por encontrarse varios metros por debajo de la cota máxima de afección de la intervención.

Fachada de la Real Casa de la Moneda: bajo la dirección de Gregorio Mora, en las fincas Adolfo Rodríguez Jurado 3, 5 y 7 (2009) y Santander 1(2012), se han documentado sendas torres de planta cuadrangular, dispuestas en oblicuo y que conforman un vano de 3’30 m de anchura, erigidas con tapias que presentan una elevada proporción de cal y un color exterior grisáceo, correspondientes al primitivo acceso del recinto amurallado en este punto de la medina y al que se asigna una cronología almorávide entre 1125 y 1134 . En un momento posterior, se erigió un muro construido con tapias de color anaranjado, que describe ante la puerta un recodo, al configurar un espacio a cielo abierto de cinco metros de longitud por trece de anchura, perteneciente al acceso que permitiría el tránsito entre las alcazabas interior y exterior desde 1170-1171 (Mora, $2009 ; 2010 ; 2013)$. Sin embargo, como quiera que no se alcanzaron los niveles de cimentación, los únicos elementos que permiten sostener las dataciones pro- 
puestas los constituyen las evidentes diferencias en la coloración de las tapias de las diferentes estructuras y las supuestas relaciones de antero-posterioridad entre ambas.

Puerta Real: dirigida en 1995 por Oscar Ramírez, se documentaron la muralla, el antemuro y el muro de la antigua Puerta de Goles, los cuales se podrían agrupar en dos fases constructivas. La primera correspondería a la muralla, cuya construcción, pese a no excavarse su cimentación, se identificó con la reedificación, por Abū Ya'qūb, de los lienzos del río, tras la inundación del año 1168-1169. La segunda estaría integrada por la puerta, como corrobora el hecho de que presentase, a consecuencia de un proceso de colmatación, una cota superior a la de la muralla, a la que se adosaba (Ramírez y Vargas, 1995, 85 ss.).

\section{Y VARIAS HIPÓTESIS.}

\subsection{Primera hipótesis.}

Como quiera que en las dos fases detectadas en las murallas de Išbīlia se documenta la utilización de tapias de hormigón de cal, no parece conveniente emplear este criterio como elemento que contribuya a proporcionar una cronología precisa a la primera de ellas, en la medida en que las similitudes en la composición, metrología, cajonamiento y coloración dificulta distinguir procesos diferentes entre ambas (Jiménez Martín, 2007, 31). Además, se ha afirmado para el conjunto de al-Andalus que la continuidad en materiales y recursos constructivos dificulta extraordinariamente diferenciar las obras almorávides de las más antiguas almohades en función de las características de las tapias (Gurriarán y Sáez, 2002, 607,611 y 612).

Por último, conviene tener en cuenta las palabras de Manuel Acién y Patrice Cressier, quienes afirman que "Tenemos que librarnos de la tentación de considerar que cada dinastía va a definir e imponer un aparejo como parte de su discurso identitario" (Acién y Cressier, 2009, 190). Por el contrario, los aspectos que más diferencian a las fortalezas son los de orden estilístico, morfológicos y topográficos.

En este sentido, a pesar de que en Sevilla se ha llevado a cabo un Proyecto de Investigación "Propuestas de mantenimiento, evaluación y restauración para la rehabilitación de edificios e infraestructuras urbanas con fábricas históricas de tapial en la Provincia de Sevilla” (2004-2008), financiado por el Ministerio de Ciencia y Tecnología (Graciani et al., 2005), sus investigadores concluyen que las diferen- cias detectadas en el que denominan tapial simple o monolítico "no parecen responder a razones evolutivas, sino a particularidades materiales o funcionales" (Graciani y Tabales, 2008, 141).

De este modo, un elemento que puede contribuir a proporcionar una datación a la primera fase sevillana lo constituye la ausencia de fábricas complementarias de las tapias en sus torres. Por el contrario, en la segunda mitad del siglo VI/XII se generaliza el recurso de trabar las aristas de las torres mediante mampuestos, ladrillos o sillares (Eslava, 1989, 55; Gurriarán, 2000, 113; Gurriarán y Sáez, 2002, 612-613; Graciani y Tabales, 2008, 141-143; Graciani, 2009, 117). Este recurso se documenta en sendas torres del Alcázar de Sevilla para las que se sostiene una cronología almohade (Valor, 1991, 96$97 ; 1993,385)$, pero en ninguna de la cerca urbana.

\subsection{Segunda hipótesis.}

El análisis tipológico de la primera fase del recinto sevillano lo aleja del aspecto de las fortificaciones consideradas típicamente almohades (figura 10) (Márquez y Gurriarán, 2008). En ese sentido, son evidentes las diferencias entre la primera fase de la muralla de Sevilla y los recintos almohades de Alcácer do Sal (Carvalho et al., 2007), Elvas (Correia, 1996; 2002), Silves (Gomes, 2002; 2003; 2006; 2009, 81-82; Gomes y Gomes, 1992), Cáceres (Torres Balbás, 1948; Valdés, 1991, 554; Márquez y Gurriarán, 2003), Badajoz (Torres Balbás, 1941; Valdés, 1991, 553-554; 1999; Márquez y Gurriarán, 2012), Marchena (Ravé, 1993, 49-50; Bellido, 2008a; 2008b; 2010), Écija (Hernández et al., 1951, 212 ss.; Romero y Carrasco, 1997; Collado et al., 2001; Carrasco y Vera, 2003; Sáez et al., 2002; 2004, 100 ss.), Jerez de la Frontera (Menéndez y Reyes, 1987a; 1987b; Montes y González, 1990; Aguilar, 1995; 2000; Barrionuevo y Aguilar, 2001; González y Aguilar, 2011) o Andújar(Eslava y Córcoles, 1980, 24, 26, 35 y 36; Salvatierra et al., 1988-1990, 86 y 88; Choclán y Castillo, 1991; Palomino, 1998, 341-342), por sólo citar algunos ejemplos.

Al respecto, una pregunta evidente es la de por qué no figuran en la primera fase del recinto sevillano los dispositivos poliorcéticos habituales en las fortificaciones de los Unitarios si hubieran sido ellos los autores de dicha fase.

Por el contrario, el análisis tipológico pondría de manifiesto que su primitivo aspecto sería muy semejante al recinto de Marrakech, erigido por orden del emir 'Alī ibn Yūsuf en 520/1126, es decir simple 
y bajo, sin decoración alguna y que se caracterizaría por torres con terraza a la altura del adarve y la ausencia de corachas, antemuro y torres poligonales (figura 11).

\section{Perspectivas de Futuro.}

"Ante la falta de una información que date con seguridad el edificio, el subjetivismo investigador impone la fecha del edificio, aunque la duda metódica proponga un punto muerto historiográfico (...). No se trata de que la arquitectura sea invisible o esté olvidada, sino de la falta de agudeza visual del instrumento de análisis que su utiliza (del modelo explicativo historiográfico que actúa a modo de lente de observación). Se necesita un nuevo instrumento adecuado al problema que se tiene que resolver" (Caballero, 2009, 157).

Tal y como afirmábamos al comienzo de estas páginas, en el estado actual de la investigación, la historiografía sevillana se encuentra dividida entre quienes afirmamos que la primera fase del recinto sevillano fue erigida entre 519/1125 y 528/1133-1134 y quienes sostienen que fue obra de los almohades. En este sentido, como quiera que Magdalena Valor, la más activa y resuelta partidaria de la segunda hipótesis, ha adelantado la datación de dicha fase hasta situarla en la primera década de dominio almohade de la ciudad, entre 1150 y $1157^{18}$, el

18 En su tesis doctoral, defendida en 1989 y publicada en 1991, distinguía dos fases constructivas, ambas obra "de unos mismos constructores o mejor, de un período muy cercano en el tiempo", como pondrían de manifiesto sus características tipológicas. La primera la dataría, de manera imprecisa, en la segunda mitad del siglo XII, mientras que la segunda, a la que correspondería el recrecimiento de la muralla, el antemuro, el foso y los lienzos del río, la sitúa a comienzos del siglo XIII (Valor, 1991, 216), cronología que repetiría en un artículo de 1994 (Valor, 1994, 648).

Un año más tarde publicaría una versión más elaborada en su aportación al catálogo de la exposición El último siglo de la Sevilla islámica (1147-1248). Así, bajo el emirato de Abū Ya'qūb, esto es entre 1163 y 1168, la cerca de la ciudad se ampliaría desde la Puerta de Carmona hasta el Postigo del Aceite; dicha ampliación se vincularía a la necesidad de disponer de amplios espacios en los que dar cabida a una población numerosa, así como almacenar y producir alimentos con los que hacer frente a una estrategia bélica en la que el asedio por hambre se erige en protagonista. Durante su califato, es decir a partir de 1168, decidió unir la ciudad con los recintos palatinos, para lo que construiría, en 1171, el muro de la puerta de Ŷahwar, muro que enlazaría ésta con la Torre del Agua, y el del lado del río; así el muro de Ŷahwar constituye el prototipo del cambio que la arquitectura militar almohade, al igual que la religiosa (alminar de la intervalo temporal que separa, a día de hoy, ambas posturas apenas es de un cuarto de siglo.

Por lo tanto, este último apartado tiene como objetivo el de plantear nuevas líneas de aproximación a la primera fase del último recinto amurallado de madīnat Išbīlia que permitan zanjar, algún día, la polémica sobre su autoría. Al respecto, no cabe la menor duda de que la última palabra sobre la fecha de erección del recinto sevillano la tendrá la arqueología. No obstante, en este momento no se encuentra en condiciones de contribuir de manera decisiva al debate sobre la cronología del mismo, pues, como ya se ha indicado, no es posible, a día de hoy, diferenciar el material cerámico de las décadas de 1120 y 1130 del de la década de 1150. Del mismo modo, ya se han señalado las dificultades técnicas que supone excavar la zanja de cimentación de la muralla.

Por lo tanto, como no es previsible que en un futuro inmediato se produzcan avances relevantes en este sentido, el recinto amurallado de Sevilla se puede estudiar desde la perspectiva de la evolución urbanística de Išbīlia, relacionando los datos proporcionados por las intervenciones arqueológicas con la hipótesis elaborada por Julio Navarro y Pedro Jiménez, en la que se sostiene la existencia de cuatro fases en la evolución de una medina ${ }^{19}$.

mezquita aljama) y la civil (Patio del Yeso), experimentaría con este califa, plasmándose en las verdugadas de ladrillo de las torres (Valor, 1995, 53-56).

Finalmente, en un artículo publicado en el número 4 de la revista Qurtuba, en colaboración con José Ramírez, afirma que "es en la época de los gobernadores anteriores a Yusuf Abu Yaqub cuando hay que buscar el levantamiento de gran parte de la cerca" (Ramírez y Valor, 1999, 176), mientras que en su ponencia, en solitario, en las Actas do Simposio Internacional sobre Castelos sostiene que "probablemente el entonces gobernador de Isbiliya Abu Yaqub impulsó una primera ampliación en el año 1159" (Valor, 2002b, 319). Dicha datación, la relaciona con un pasaje del Mann de Ibn Sāhib al-Salāt, en el que se narra que, cuando Ibn Mardanīš atacó Sevilla el año 554/1159-1160, “(...) la fortaleció el sayyid ilustre Abū Ya'qūb con su dicha y su esfuerzo y su gran suerte" (Ibn Sāhib al-Salāt, 1969, 13). Dicho pasaje es interpretado como "la única mención de una construcción en Sevilla en la etapa de valí (gobernador) del príncipe Abu Yaqub Yusuf” (Valor, 2008a, 31).

19 Estas fases se denominan constitución, expansión, saturación y desbordamiento y cada una de ellas se caracteriza por una realidad arqueológica propia (Navarro y Jiménez, $2003 ; 2007)$. Su aplicación ya se ha ensayado para madīnat Išbīlia por Magdalena Valor (Valor y Tabales, 2004; Valor, 2008a, 179-184; 2009b, 315-316) y por nosotros mismos (Jiménez y Pérez, 2012, 307 ss.). 


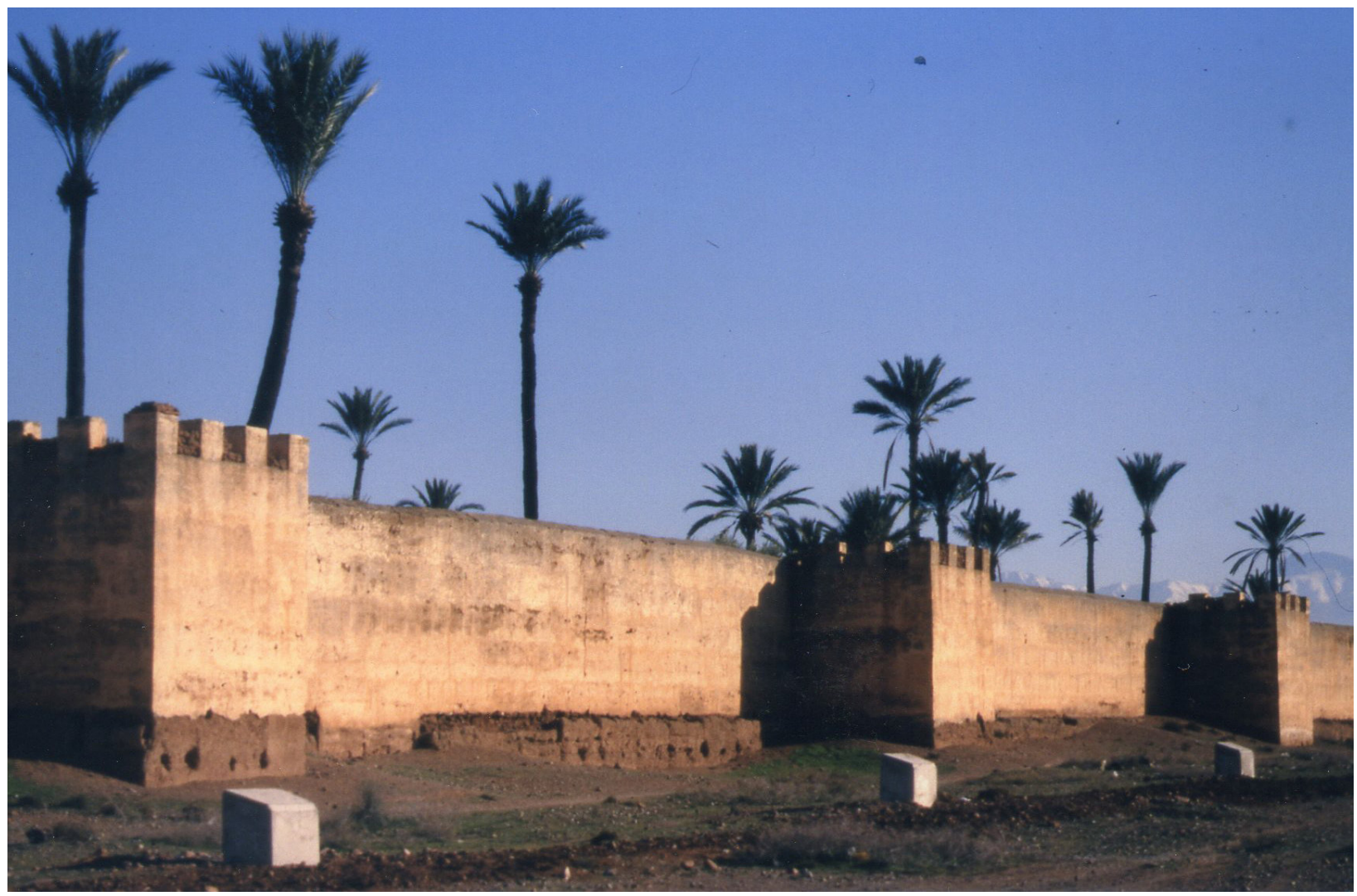

Figura 11. Vista de las murallas almorávides de Marrakech (fotografía de Daniel Jiménez). Erigidas casi al mismo tiempo que el recinto sevillano, su aspecto sería muy similar.

La aplicación de mencionado modelo teórico permite sostener que la erección del último recinto amurallado de la ciudad de Sevilla fue el resultado del proceso evolutivo sufrido por madīnat Išbīlia desde el año 93/712 y que alcanzó su punto culminante a comienzos del siglo VI/XII.

En esta fecha, su medina había experimentado las fases de expansión, en el transcurso de la cual cementerios e instalaciones artesanales fueron expulsados de la misma, de saturación, que puede intuirse en las sucesivas fases constructivas que se superponen en algunas intervenciones de su periferia, y de desbordamiento, sobre todo en su flanco septentrional y a lo largo de las actuales calles Bustos Tavera-San Luis y Sol (figura 12) (Jiménez Maqueda y Pérez, 2012, 309 ss.).

\section{BiBliografía.}

Acién, M. y Cressier, P. (2009), "Fortalezas dinásticas del Marruecos medieval: aspectos constructivos”, Monografías Conjunto Monumental de la Alcazaba $n^{\circ}$ 2. Construir en al-Andalus, Almería, 173-203.
Aguilar, L. (1995), "Excavaciones de urgencia. C/ Muro. Año 1992. Jerez de la Frontera", Anuario Arqueológico de Andalucía / 1992, III, 115-118.

(2000), "Nuevos datos sobre las murallas islámicas de Jerez de la Frontera", Revista de Historia de Jerez, 6, 99-113.

Alba, M. de y Tabales, M.A. (2008), Memoria preliminar Intervención Arqueológica Preventiva en Calle Sol, $n^{\circ}$ 122. Análisis de la muralla islámica en el sector oriental de Sevilla, Documento interno de la Delegación Provincial en Sevilla de la Consejería de Cultura de la Junta de Andalucía.

Amores, F. (1993), "Memoria de la intervención arqueológica en c/Torneo n ${ }^{0} 26$ (Sevilla)”, Anuario Arqueológico de Andalucía/1991, III, 449453.

(2007), "La intervención arqueológica", La Torre del Oro y Sevilla, Sevilla, 173-190.

(2010), "Análisis arqueológico de los paramentos y sondeos en las escalinatas exteriores de la Torre del Oro (Sevilla)", Anuario Arqueológico de Andalucía/ 2004,2, 848-861. 


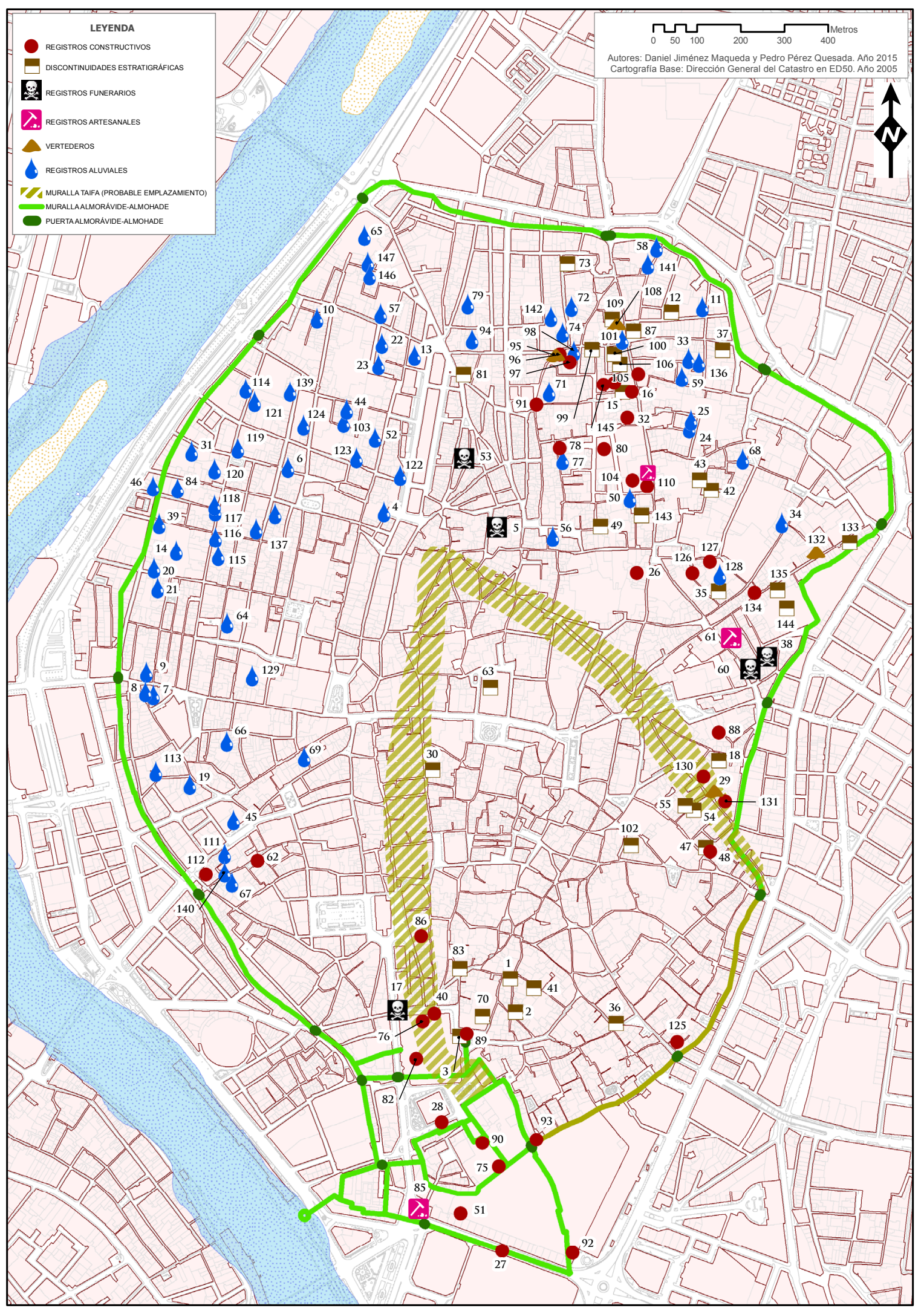

Figura 12. Hipótesis sobre la Išbīlia almorávide. 
Amores, F. y Quirós, A. (1999), “Las Atarazanas: el tiempo y los usos", Recuperando las Atarazanas. Un monumento para la cultura, Sevilla, 35-56.

Amores, F., Rodríguez, J.M. y Campos, J.M. (1987), "Excavaciones en las murallas medievales de Sevilla. Sector coracha Torre del Oro", Anuario Arqueológico de Andalucía / 1985,III, 343-345.

Azuar, R. (2004), "Técnicas constructivas y fortificación almohade en al-Andalus", Los almohades. Su patrimonio arquitectónico y arqueológico en el sur de al-Andalus, Sevilla, 57-74.

(2005), "Aspectos simbólicos de la arquitectura militar almohade. El falso despiece de sillería y las bóvedas de arcos entrecruzados", Los almohades: problemas y perspectivas, I, Madrid, 123-147.

Azuar, R. y Ferreira, I.C. (2014), "La fortificación del califato almohade", Las Navas de Tolosa 1212-2012. Miradas cruzadas, Jaén, 395-420.

Azuar, R., Lozano, F.J., Llopis, T.Mª y Menéndez, J.L. (1996), "El falso despiece de sillería en las fortificaciones de tapial de época almohade en alAndalus", Estudios de Historia y de Arqueología Medievales, XI, 245-278.

Barrionuevo, F. y Aguilar, L. (2001), "Intervenciones arqueológicas de urgencia en Jerez de la Frontera, Cádiz c/Larga 61-63 y c/Francos 36”, Anuario Arqueológico de Andalucía / 1997,III, 68-72.

Bellido, T. (2008a), "La muralla medieval de Marchena. Análisis arqueológico”, Romvla, 7, 299330.

(2008b), "Análisis estratigráfico en la muralla medieval de Marchena (Sevilla)", Arqueología de la Arquitectura, 8, 159-185.

(2010), Análisis arqueológico de las murallas de Marchena, Sevilla.

Bosch, J. (1984), Historia de Sevilla. La Sevilla islámica (712-1248), Sevilla.

Caballero, L. (2009), "Reflexiones a partir del estudio de aparejos constructivos altomedievales", Monografías Conjunto Monumental de la Alcazaba $n^{\circ}$ 2. Construir en al-Andalus, Almería, 141-172.

Cabra, M르. y Santiago, E.M ${ }^{\mathrm{a}}$ (1988), Iconografía de Sevilla 1400-1650, Sevilla.

Campos, J.M. y Moreno, Mª T. (1988), “Excavaciones en la muralla medieval de Sevilla. El lienzo de la Macarena”, Archivo Hispalense. Revista Histórica, Literaria y Artística, 218, 187-206.

Campos, J.M., Moreno, MªT. y Vera, M. (1987), "Investigaciones arqueológicas del recinto de la antigua Casa de la Moneda. Sector Patio de los Capataces", Anuario Arqueológico de Andalucía/1986,III, 298-302.

Campos, J.M., Moreno, Mำ., Vera, M., y Amores, F. (1987), "Excavaciones en el lienzo de muralla medieval de la Macarena”, Anuario Arqueológico de Andalucía / 1985,III, 350-356.

Campos, J.M., Vera, M., y Moreno, Mª T. (1987), "Investigaciones arqueológicas en el recinto de la antigua Casa de la Moneda. Sector Fundición”, Anuario Arqueológico de Andalucía/1986, III, 291-297.

Carrasco, I. et al. (2013), "La historia del patio de San Laureano de Sevilla a través de las excavaciones arqueológicas (2002-2007)”, Archivo Hispalense. Revista Histórica, Literaria y Artística, 291-293, 119-167.

Carrasco, I. y Vera, E. (2001), “Intervención arqueológica de urgencia en un inmueble sito en calle Julio César 14 esquina a Canalejas de Sevilla”, Anuario Arqueológico de Andalucía/1998,III-2, 697705 .

(2003), "Intervención arqueológica de urgencia en c/ Bodegas 5 esquina a c/ Merinos. Écija (Sevilla)", Anuario Arqueológico de Andalucía/2000,III-2, 1288-1297.

Caro, R. (1634), Antigüedades y Principado de la Ilustrissima Ciudad de Sevilla y Chorografia de su Convento Iuridico o Antigua Chancillería, Sevilla.

Carvalho, A.R., Faria, J.C. y Ferreira, M.A. (2007), (Al-Qasr). Alcácer do Sal. Arqueologia e Historia de uma Madina do Garb al-Andalus (Séculos VIII-XIII), Alcácer do Sal.

Chisvert, N. (1994), Informe de la intervención arqueológica en el solar de la calle Resolana $n^{\circ}$ 41. Sevilla, Documento interno de la Delegación Provincial en Sevilla de la Consejería de Cultura de la Junta de Andalucía.

Choclán, C. y Castillo, J.C. (1991), "Excavación de urgencia en el solar C/ San Francisco, 3 y C/ Juan Robledo, 12 de Andújar”, Anuario Arqueológico de Andalucía / 1989,III, 319-327.

Collado, A., Romero, C. y Carrasco, I. (2001), "Intervención arqueológica de urgencia en un solar sito en la calle Merinos $n^{\circ} 38$ de Écija. Sevilla”, Anuario Arqueológico de Andalucía/1996, I, 657-663.

Collantes de Terán, F. (1957), "La Sevilla que vio Guzmán el Bueno”, Archivo Hispalense, 84-85, 9-44. 
(1968), Inventario de los Papeles del Mayordomazgo del siglo XIV, Sevilla.

(1972), Inventario de los Papeles del Mayordomazgo del siglo XV (1401-1416), Sevilla.

(1977), Contribución al estudio de la topografía sevillana en la antigüedad y en la edad media, Sevilla.

Cómez, R. (2008), "La Torre del Oro, revisitada”, Archivo Hispalense, 276-278, 237-265.

Correia, F.B. (1987), "Fortificações musulmanas em Portugal: alguns apontamentos", II Congreso de Arqueología Medieval Española, II, Madrid, 501-509.

(1996), "Espaços fortificados de época e influencia islámica na margen direita do curso médio de Guadiana”, Bataliús: el reino taifa de Badajoz: estudios, Madrid, 77-88.

(2002), "O sistema defensivo da Elvas Islâmica”, Mil Anos de Fortificações na Península Ibérica e no Magreb (500-1500), Lisboa, 357-367.

Domínguez, E. (2003), Teoría y práctica de la crítica historiográfica. Transformaciones socioproductivas y procesos urbanos en IšbīliaSevilla (ss. XI-XIII), Tesis doctoral de la Universidad de Sevilla.

(2008), "Sevilla y las fortificaciones fluviales del Guadalquivir", Actas $4^{\circ}$ Congreso Internacional sobre Fortificaciones: Las fortificaciones y el mar. Alcalá de Guadaira, Alcalá de Guadaira, 231-250.

(2014), "Ishbilia entre dos mundos: arqueología de la Sevilla andalusí", Sevilla Arqueológica. La ciudad en época protohistórica, antigua y andalusí, Sevilla, 212-269.

Domínguez, E. y Amores, F. (2009), “Actividad arqueológica puntual toma de muestras y sondeo exterior en la Torre del Oro (Sevilla)", Anuario Arqueológico de Andalucía/2004, 1, 35243532.

Escudero, J., Moreno, Mª T. y Lorenzo, J. (1990), "La muralla medieval de Sevilla. Intervención en el lienzo conservado en la calle Tintes 5-7-9", Anuario Arqueológico de Andalucía / 1987,III, 595-602.

Eslava, J. (1989), "Fortificaciones de tapial en alAndalus y al-Magreb”, Castillos de España, 98, 52-55.

Eslava, J. y Córcoles, J.V. (1980), “Las fortificaciones medievales de Andújar", Boletín del Instituto de Estudios Giennenses, 102, 9-40.

Fernández, A. y Rodríguez, A. (2003), “Interven- ción arqueológica en Calle Diego de Deza 3 y 5 de Sevilla. Evolución edilicia de la cerca islámica tras la conquista cristiana. Siglos XIV-XX”, Anuario Arqueológico de Andalucía/2000, III-2, 971991.

Gomes, R.V. (2002), "Estructuras defensivas medievais de Silves", Mil Anos de Fortificações na Península Ibérica e no Magreb (500-1500, Lisboa, 325-336.

(2003), Silves (Xelb), uma cidade do Gharb AlAndalus: a Alcáçova, Trabalhos de Arqueologia, 35, Lisboa.

(2006), Silves (Xelb), uma cidade do Gharb AlAndalus: o núcleo urbano, Trabalhos de Arqueologia, 44, Lisboa.

(2009), "Silves y las fortificaciones del Gharb AlAndalus (siglos XII-XIII)", El castillo medieval en tiempos de Alfonso X el Sabio, Murcia, 78-98.

Gomes, R.V. y Gomes, M.V. (1992), "Dispositivos defensivos de Silves (Algarve, Portugal)", III Congreso de Arqueología Medieval Española, II, Oviedo, 287-292.

González, R. (2006), "La arqueología islámica de Jerez: una visión desde la arqueología urbana”, $M e$ dinas y ciudades históricas a ambos lados del Estrecho: Jerez y Tetuán, Jerez, 79-98.

González, R. y Aguilar, L. (2011), El sistema defensivo islámico de Jerez de la Frontera: Fuentes para su reconstrucción virtual, Almería.

Graciani, A. (2008), "Propuesta de metodología científica para la caracterización constructiva de fábricas de tapial en los estudios previos. Su aplicación a la muralla de Sevilla en el tramo del Jardín del Valle”, IX Congreso Internacional de Rehabilitación del Patrimonio Arquitectónico y Edificación. Patrimonio Cultural e Innovación, I, Gran Canaria, 51-56.

(2009), "La técnica del tapial en Andalucía Occidental”, Monografías Conjunto Monumental de la Alcazaba $n^{o}$ 2. Construir en al-Andalus, Almería, 111-140.

Graciani, A. et al. (2005), "Revisión crítica de las analíticas sobre las fábricas de tapial en la muralla islámica de Sevilla”, I Jornadas de Investigación en Construcción, Madrid, 213-222.

Graciani, A. y Tabales, M.A. (2008), "El tapial en el área sevillana. Avance cronotipológico estructural”, Arqueología de la Arquitectura, 5, 135158.

Guerrero Lovillo, J. (1953), "La puerta de Córdoba 
en la cerca de Sevilla”, Al-Andalus, XVIII, 178187.

(1972), "Sevilla musulmana”, Historia del urbanismo sevillano, Sevilla, 23-45.

Gurriarán, P. (2000), “Arquitectura y técnicas constructivas en al-Andalus durante la época almohade", Historia de las técnicas constructivas en España, Madrid, 109-121.

Gurriarán, P. y Sáez, A.J. (2002), "Tapial o fábricas encofradas en recintos urbanos andalusíes", II Congreso Internacional La ciudad en alAndalus y el Magreb, Granada, 561-625.

Herce, J.P. (1996), Informe de la intervención arqueológica de urgencia en $M^{a}$ Auxiliadora 39. Sevilla, Documento interno de la Delegación Provincial en Sevilla de la Consejería de Cultura de la Junta de Andalucía.

Herce, J.P. y Franco, C. (1997), Memoria cientifica de las intervenciones arqueológicas de urgencia en c/ Sol 128 y 130-134. Sevilla, Documento interno de la Delegación Provincial en Sevilla de la Consejería de Cultura de la Junta de Andalucía.

Hernández, J., Sancho, A. y Collantes de Terán, F. (1951), Catálogo Arqueológico y Artístico de la provincia de Sevilla, III, Sevilla.

Huici, A. (1953), Colección de Crónicas Árabes de la Reconquista. Volumen II. Al-Bayān almugrib fi ijtisār ajbār muluk al-Andalus wa al-Magrib por Ibn 'I $\underline{d} \bar{a} r \bar{\imath}$ al-Marrākūǔš. Los Almohades. Tomo I, Tetuán.

(1955), Colección de Crónicas árabes de la Reconquista. Volumen IV. Kitāb al-mu'ŷ̀ib fī taljīs ajbār al-Magrib por Abu Muhammad 'Abd al-Wāhid al-Marrākuš̄i, Tetuán.

Hunt, M.A. et al. (2010), "Excavación arqueológica en la "Estación Puerta de Jerez", Fase I-A. Línea 1 del Metro de Sevilla (calle San Fernando, Sevilla)", Anuario Arqueológico de Andalucía/2006, Sevilla, 4481-4512.

Ibn Abī Zar' (1964), Rawd al-qirtās (Traducido y anotado por Ambrosio Huici), Valencia.

Ibn 'Id̄̄āī (1963), Al-Bayān al-Mugrib. Nuevos fragmentos almorávides y almohades (Traducidos y anotados por Ambrosio Huici), Valencia.

(1993), La caída del califato de Córdoba y los reyes de taifas (al-Bayān al-Mugrib) (Estudio, traducción y notas por Felipe Maillo), Salamanca.

Ibn Sāhib al-Salāt (1969), Al-Mann bi-l-Imāma (Estudio preliminar, traducción e índices por Ambrosio Huici), Valencia.
Jiménez Maqueda D. (1996a), "Algunas precisiones cronológicas acerca de las murallas de Sevilla”, Laboratorio de Arte, 9, 11-22.

(1996b), "La puerta de la Macarena. Un ejemplo de dispositivo poliorcético almohade en la muralla almorávide de Sevilla”, Norba-Arte, XVI, 7-17.

(1998a), "Algunas precisiones cronológicas sobre las murallas de Sevilla”, I Congreso Internacional Fortificaciones en al-Andalus, Algeciras, 333339.

(1998b), "¿Era la Bāb ŶYahwar la puerta de la Carne?", Laboratorio de Arte, 11,395-404.

(1998c), "Las murallas de Sevilla. Una aproximación historiográfica”, Archivo Hispalense, 248, 9-31.

(1999a), Las puertas de Sevilla. Una aproximación arqueológica, Sevilla.

(1999b), "Las puertas medievales y postmedievales de la ciudad de Sevilla. Una aproximación históricoarqueológica”, Cuadernos de la Alhambra, 35, 149-159.

(2007), "Las murallas y las puertas”, La Sevilla de Richard Ford 1830-1833, Sevilla, 167-180.

Jiménez Maqueda, D. y Pérez, P. (2012), "La muralla huérfana. A vueltas con el último recinto amurallado de madīnat Išbīlia”, Romvla, 11, 273-347.

Jiménez Martín, A. (1981), "Análisis formal y desarrollo histórico de la Sevilla medieval”, La arquitectura de nuestra ciudad, Sevilla, 11-29.

(2000), "La explanada de Ibn Jaldún. Espacios civiles y religiosos de la Sevilla almohade", Sevilla 1248. Congreso Internacional Conmemorativo del 750 Aniversario de la Conquista de la ciudad de Sevilla por Fernando III, Rey de Castilla y León, Madrid, 43-71.

(2007), "La ciudad almohade y los Caños de Carmona”, La Catedral en la ciudad (III). Los Caños y los difuntos. Primer tomo, Sevilla, 21-48.

Jiménez Sancho, A. (2002a), "Seguimiento arqueológico en la Puerta del Perdón de la $\mathrm{Ca}-$ tedral de Sevilla", Anuario Arqueológico de Andalucía /1999,III-2, 899-908.

(2002b), "Seguimiento arqueológico en las gradas de la Puerta del Perdón”, Magna Hispalensis (I). Recuperación de la aljama almohade, Granada, 339-361.

(2002c), "Intervención arqueológica en el Patio de los Naranjos", Magna Hispalensis (I). Recuperación de la aljama almohade, Granada, 363401.

(2003), "Excavación en el Patio de los Naran- 
jos de la Catedral de Sevilla. Una mezquita amurallada”, Anuario Arqueológico de Andalucía /2000,III-2, 905-922.

(2014), "Arqueología en la Catedral de Sevilla”, Sevilla Arqueológica. La ciudad en época protohistórica, antigua y andalusí, Sevilla, 270-273.

Jofre, C.A. y Rodríguez, A. (2005), "Excavación arqueológica de urgencia en c/Torneo esquina a c/Lumbreras", Anuario Arqueológico de Andalucia/2002,III-2, 277-288.

León, A. (2003), Las fortalezas de Belalcázar (Córdoba): análisis arqueológico de su arquitectura (s. IX-XIX), Córdoba.

(2004), "Recensión a Miguel Ángel Tabales: El Alcázar de Sevilla. Primeros estudios sobre estratigrafía y evolución constructiva”, Romvla, 3, 311-317.

López, R. (2007), Intervención Arqueológica Preventiva en calle Santander 15, Documento interno de la Delegación Provincial en Sevilla de la Consejería de Cultura de la Junta de Andalucía.

Lorenzo, J., Rueda, M. y Escudero, J. (1987), “Investigaciones arqueológicas en las murallas medievales de Sevilla: calle Marqués de Paradas 29-35", Anuario Arqueológico de Andalucía/1986, III, 303-306.

Márquez, S. y Gurriarán, P. (2003), "La muralla almohade de Cáceres: aspectos constructivos, formales y funcionales", Arqueología y Territorio Medieval, 10.1, 57-118.

(2008), "Recursos formales y constructivos en la arquitectura militar almohade de al-Andalus", $A r$ queología de la Arquitectura, 5, 115-134.

(2012), "Tras las huellas de los almohades. Reflexiones sobre las últimas fortificaciones del Badajoz andalusí", Cuadernos de Arquitectura y Fortificación, 0, 55-76.

Martín, J.J., Alejandre, F.J., Blasco, F.J., y Márquez, G. (2008), "Hormigones de cal islámicos: altas resistencias en los tapiales del sector oriental de la muralla de Sevilla (España)", IX Congreso Internacional de Rehabilitación del Patrimonio Arquitectónico y Edificación. Patrimonio Cultural e Innovación, I, Gran Canaria, 81-86.

Mata, J. (2010), Memoria final: Actividad Arqueológica Preventiva en C/ Zaragoza $n^{\circ} 8$ (Sevilla), Documento interno de la Delegación Provincial en Sevilla de la Consejería de Cultura de la Junta de Andalucía.

Mejías, J.C., González, Mª A. y Mercado, L. (2001), "Intervención arqueológica de urgen- cia en el solar $\mathrm{n}^{\circ} 24$ de la calle Muro de los $\mathrm{Na}$ varros (Sevilla)", Anuario Arqueológico de Andalucía/1998,III-2, 769-777.

Menéndez, J.L., Azuar, R., Lozano, F.J., y Llopis, T.Ma (1998), "El falso despiece de sillería en las fortificaciones de tapial de época almohade en Al-Andalus", Actas del I Congreso Internacional de Castellología Ibérica, Palencia, 481-511.

Menéndez, Mª́ y Reyes, F. (1987a), "El Alcázar de Jerez de la Frontera”, Actas del I Congreso de Arqueología Medieval Española, Zaragoza, 307-324.

(1987b), "Estructuras defensivas de una ciudad almohade: Jerez de la Frontera", II Congreso de Arqueología Medieval Española, II, Madrid, 765-772.

Montes, C. y González, R. (1990), "Excavaciones arqueológicas en el casco urbano de Jerez. Año 1987. C/ Larga 21-25 y C/ Lancería 3-7", Anuario Arqueológico de Andalucía/1987/III, 99108.

Mora, G.M. (2009), "Otro ensayo de arqueología aplicada al conocimiento de edificios históricos. La Real Casa de la Moneda de Sevilla”, Actas del Sexto Congreso Nacional de Historia de la Construcción, Madrid, 929-938.

(2010), “A vueltas con la muralla de Sevilla ¿Puertas o portillos? Resultados de la Arqueología aplicada a la portada de la Real Casa de la Moneda de Sevilla”, V Congreso Internacional sobre Fortificaciones. Fortificación y ciudad, Sevilla, 6776.

(2013), La Casa de la Moneda de Sevilla. Patrimonio inmueble y relación con el entorno, Tesis doctoral de la Universidad de Sevilla.

Moreno, Mํㅜ․, Vera, M. y Campos, J.M. (1987), “Investigaciones arqueológicas en las murallas medievales de Sevilla. Sector Jardines del Colegio del Valle", Anuario Arqueológico de Andalucía/ 1986, III, 285-290.

Morón, M ${ }^{a} F$. (1998), "Las maquetas de la ciudad de Sevilla del año 1511”, La Catedral virtual. $\mathrm{Cu}$ rricula y resúmenes, Sevilla, 13-14.

Navarro, J. y Jiménez, P. (2003), "Sobre la ciudad islámica y su evolución”, Estudios de arqueología dedicados a la profesora Ana María Muñoz Amilibia, Murcia, 319-381.

(2007), Las ciudades de al-Andalus. Nuevas perspectivas, Zaragoza.

Ormad, E. y Pecero, J.C. (1997), Informe sobre seguimiento arqueológico en el solar Juan 
de Rabadán $n^{\circ}$ 58/esquina calles Torneo y Eduardo Cano. Sevilla, 1997, Documento interno de la Delegación Provincial en Sevilla de la Consejería de Cultura de la Junta de Andalucía.

Ortega, M. (2002), “Intervención arqueológica de urgencia en María Auxiliadora $\mathrm{n}^{\mathrm{o}}$ 37 (Sevilla)", Anuario Arqueológico de Andalucía / 1999,III-2, 685-696.

Palomino, J. (1998), "Las murallas de la ciudad de Andújar y su pervivencia a través de las Actas Capitulares y el urbanismo", I Congreso Internacional Fortificaciones en al-Andalus, Algeciras, 341-345.

Pavón, B. (1993), Ciudades y fortalezas lusomusulmanas. Crónica de viajes por el sur de Portugal, Madrid.

(1999), Tratado de arquitectura hispanomusulmana II. Ciudades y fortalezas, Madrid.

Peláez, Mª̊ y Gómez, A. (1991), "Seguimiento de la muralla medieval de Sevilla. Excavaciones arqueológicas de urgencia en la calle Torneo núm. 23", Anuario Arqueológico de Andalucía / 1989,III, 437-440.

Peraza, L. de (1979), Historia de Sevilla (Transcripción, estudio y notas por Francisco Morales Padrón), Sevilla.

(1997), Historia de la ciudad de Sevilla (Edición, introducción e índices por Silvia María Pérez González), Sevilla.

Pozo, F. (2001a), "Seguimiento arqueológico de obras en solar de c/ Torneo 47 (Sevilla)", Anuario Arqueológico de Andalucía/1998, III-2, 729-733.

(2001b), "Seguimiento arqueológico de obras en solar de c/ Torneo 48-49 (Sevilla)", Anuario Arqueológico de Andalucía / 1998, III-2, 734-738.

(2003a), "Control arqueológico de los movimientos de tierra en solar C/ Torneo 40-41 (Sevilla)", Anuario Arqueológico de Andalucía/2000, III-2, 1102-1108.

(2003b), "Control arqueológico de obras en calle María Auxiliadora n 37 (Sevilla)", Anuario Arqueológico de Andalucía / 2000, III-2, 1109-1117.

(2008), Memoria final de la Intervención Arqueológica Puntual en Murallas de la Macarena. Sector Puerta de Córdoba, Documento interno de la Delegación Provincial en Sevilla de la Consejería de Cultura de la Junta de Andalucía.

Pozo, F. y Somé, P. (2002), "Intervención arqueológica en solar de C/ Aguiar 5-7 (Sevilla)", Anuario Arqueológico de Andalucía /1999, III-2, 790-806.
Quirós, A. (1999), "Las Reales Atarazanas de Sevilla: preexistencias islámicas y fase fundacional del edificio”, XXIV Congreso Nacional de Arqueología, Cartagena 1997, 5, Murcia, 189-195.

Quirós, A., Romo, A.S. y Vera, M. (1995), Plaza Virgen de los Reyes. Informe de la Intervención Arqueológica, Documento interno de la Delegación Provincial de la Consejería de Cultura de la Junta de Andalucía en Sevilla.

Ramírez, J. y Valor, M. (1999), "Las murallas de Sevilla. Apuntes historiográficos y arqueológicos”, Qurtuba, 4, 167-179.

Ramírez, F.O. y Vargas, J.M. (1995), "Las murallas de Sevilla: intervenciones arqueológicas municipales”, El último siglo de la Sevilla islámica (1147-1248), Salamanca, 83-95.

Ravé, J.L. (1993), El alcázar y la muralla de Marchena, Marchena.

Rodríguez, S. (1993), "Seguimiento de obras de infraestructura en Sevilla c/ Mateos Gago y Avda. de la Constitución”, Anuario Arqueológico de Andalucía/1991,III, 430-434.

Rodríguez, S. y Ramírez, F.O. (1997), "La Catedral de Sevilla y la antigua mezquita mayor almohade. Intervención arqueológica en la Puerta de San Cristóbal”, Anuario Arqueológico de Andalucía/1993, III, 557-563.

Rodríguez, S., Ramírez, F.O. y Lafuente, P. (1994), "Excavación arqueológica en la Puerta de San Cristóbal de la Catedral de Sevilla”, Actas del IV Congreso de Arqueología Medieval Española: sociedades en transición, III, Alicante, 721726.

Romero, C. y Carrasco, I. (1997), "Excavación arqueológica en C/ Bodegas a C/ Ostos s/n. Écija. Sevilla”, Anuario Arqueológico de Andalucía 1993.III, 704-710.

Romo, A.S. (2001), "El tramo defensivo islámico de la intervención en C/Cano y Cueto-Paseo Catalina de Ribera (Sevilla)", Anuario Arqueológico de Andalucía / 1996, I, 559-566.

Romo, A.S. y Ortega, M. (2005), "De Cárcel de Caballeros a Corral de las Herrerías. La Casa de la Moneda de Sevilla", Anuario Arqueológico de Andalucía/2002, III-2, 189-204.

Romo, A.S. y Vargas, J.M. (1999), Informe de la intervención arqueológica de urgencia en el inmueble de c/ Adriano $n^{\circ} 12$ (Sevilla). Fase I-Septiembre 1999, Documento interno de la Delegación Provincial en Sevilla de la Consejería de Cultura de la Junta de Andalucía. 
Sáez, P., Ordóñez, S., García, E., y García-Dils, S. (2002), "La cerca islámica de Écija (Sevilla)", Actas Congreso Internacional: Fortificaciones en el entorno del Bajo Guadalquivir, Alcalá de Guadaira, 255-263.

(2004), Écija. 1: La ciudad: carta arqueológica municipal, Sevilla.

Salem, A.A. (1979-1980), "Obras almohades en la muralla almorávide de Sevilla”, Revista del Instituto Egipcio de Estudios Islámicos en Madrid, XX, 173-181.

Salvatierra, V., Castillo, J.C., Pérez, $\mathrm{M}^{\mathrm{a}} \mathrm{C}$., y Castillo, J.L. (1988-1990), "El desarrollo urbano en alAndalus: el caso de Andújar (Jaén)”, Cuadernos de Madīnat al-Zahrā', 2, 85-107.

Sancho, A. (1975), Iconografía de Sevilla, Sevilla.

Sardá, D. et al. (2003), "Intervención arqueológica de urgencia en la Avenida Menéndez Pelayo, nums. 5 y 7", Anuario Arqueológico de Andalucía/2000, III-2, 1131-1142.

Tabales, M.A. (2001), "Intervención arqueológica en c/ Menéndez Pelayo $n^{\circ} 19$. El antemuro de la muralla islámica en el sector oriental de Sevilla", Anuario Arqueológico de Andalucía/1996, I, 475-485.

(2002a), "Contribución al estudio de la cerca islámica de Sevilla. Investigaciones en c/ Menéndez y Pelayo 43-45", Anuario Arqueológico de Andalucía/1999, III-2, 716-734.

(2002b), El Alcázar de Sevilla. Primeros estudios sobre estratigrafía y evolución constructiva, Sevilla.

(2002c), "Sondeos estratigráficos en el Alcázar de Sevilla. Campaña 1999”, Anuario Arqueológico de Andalucía/ 1999, II, 212-233.

Tabales, M.A. y Jiménez Sancho, A. (2001), "Intervención arqueológica en el Pabellón de Oficinas de la Catedral de Sevilla (1997-1998)", Anuario Arqueológico de Andalucía/1997, III, 429443.

(2002), "La Cilla de la Catedral y el sector meridional de la mezquita aljama de Sevilla", Magna Hispalensis (I). Recuperación de la aljama almohade, Granada, 229-296.

Tabales, M.A., Romo, A., García, E., y Huarte, P. (2001), "Análisis arqueológico del sector exterior oriental de la Catedral de Sevilla", Anuario Arqueológico de Andalucía / 1996, I, 393-404.

(2002), "Investigaciones arqueológicas en la Acera de Levante de la Catedral de Sevilla", Magna Hispalensis (I). Recuperación de la aljama al- mohade, Granada, 115-168.

Tahiri, A. (1998), "Problemas de una reconstrucción urbana en al-Andalus: el ejemplo de la Sevilla 'abbādì", Genèse de la ville islamique en al-Andalus et au Magreb occidental, Madrid, 219-227.

(2007), "Problemas para una reconstrucción urbana en al-Andalus. El ejemplo de la Sevilla 'abbādí”, Rīf al-Magrib y al-Andalus. Organización del territorio en las dos orillas del Estrecho (siglos VIII-XI), Sevilla, 87-106.

Torremocha, A. (2004), "Fortificaciones almohades en la provincia de Cádiz”, Los almohades. Su patrimonio arquitectónico y arqueológico en el sur de al-Andalus, Sevilla, 103-122.

Torres Balbás, L. (1934a), "Las torres del Oro y de la Plata en Sevilla”, Archivo Español de Arte y Arqueología, 29, 89-104.

(1934b), "La Torre del Oro en Sevilla", Al-Andalus, II, 372-373.

(1941), "La alcazaba almohade de Badajoz", Al-Andalus, VI, 168-203.

(1948), “Cáceres y su cerca almohade”, Al-Andalus, XIII, 446-472.

(1952), "Nuevas perspectivas sobre el arte de al-Andalus bajo el dominio de los Almorávides", $A l$ Andalus, XVII, 402-433.

(1955), Artes almorávide y almohade, Madrid.

Valdés, F. (1991), "La fortificación islámica en Extremadura: resultados provisionales de los trabajos en las alcazabas de Mérida, Badajoz y Trujillo y en la cerca urbana de Cáceres”, Extremadura Arqueológica, II, 547-557.

(1999), "Las etapas constructivas de la alcazaba de Badajoz”, Bataliús II. Nuevos estudios sobre el reino taifa de Badajoz, Madrid, 149-168.

Valencia, R. (1986), Sevilla musulmana hasta la caída del Califato. Contribución a su estudio, Madrid.

Valor, M. (1991), La arquitectura militar y palatina en la Sevilla musulmana, Sevilla.

(1993), "La arquitectura militar almohade en el conjunto de los Reales Alcázares de Sevilla”, Arquitectura y ciudad II y III, Madrid, 382-388.

(1994), "Las fortificaciones medievales en el Reino de Sevilla”, Arqueología en el entorno del Bajo Guadiana, Huelva, 645-655.

(1995), "Las defensas urbanas y palatinas”, El último siglo de la Sevilla islámica (1147-1248), Salamanca, 49-56.

(2002a), "De Hispalis a Isbiliya”, Edades de Sevi- 
lla. Hispalis, Isbiliya, Sevilla, Sevilla, 41-58.

(2002b), "Las fortificaciones de Sevilla", Mil Anos de Fortificações na Península Ibérica e no Magreb (500-1500, Lisboa, 319-324.

(2004), "Algunos ejemplos de construcciones defensivas almohades en la provincia de Sevilla", Los almohades. Su patrimonio arquitectónico y arqueológico en el sur de al-Andalus, Sevilla, 145-163.

(2008a), Sevilla almohade, Málaga.

(2008b), "Algunas ciudades del bajo Guadalquivir entre 1150 y 1260: Carmona, Écija, Niebla y Sevilla”, Al-Andalus. País de Ciudades, Toledo, 133-175.

(2009a), "La arquitectura defensiva desde 1147 a 1300: algunos ejemplos de Andalucía Occidental”, El castillo medieval en tiempos de Alfonso $X$ el Sabio, Murcia, 191-225.

(2009b), "Estado de la investigación histórico-arqueológica de Sevilla en época andalusí”, Xelb, 9, 297-320.

(2014), "La muralla medieval de Sevilla. Otra interpretación”, Sevilla Arqueológica. La ciudad en época protohistórica, antigua y andalusí, Sevilla, 252-253.

Valor, M. y Casquete, N. (1991), "La Torre de la Plata de Sevilla. Memoria de la excavación arqueológica practicada en su cámara inferior”, Anuario Arqueológico de Andalucía/1989,III, 432-436.

Valor, M. y Ramírez, J. (1999), "Sobre la cronología de las murallas", Sevilla almohade, Madrid, 2739.

(2000), "Las defensas de Sevilla", Sevilla. 1248. Congreso Internacional Conmemorativo del 750 Aniversario de la Conquista de la ciudad de Sevilla por Fernando III, Rey de Castilla y León, Madrid, 85-98.

Valor, M. y Tabales, M.A. (2002), "Las fortificaciones de Madina Isbiliya (Sevilla)", Cuadernos de Patrimonio Histórico 1. Ciudades amuralladas, Cuenca, 179-205.

(2004), "La estructura y evolución del casco histórico de Sevilla en época andalusí: Sevilla de medina a hadira", La ciudad en el Occidente islámico medieval. Nuevas aportaciones de la arqueología y relectura de fuentes. Preactas, Granada.

(2005), "Urbanismo y arquitectura almohades en Sevilla. Caracteres y especificidad", Los almohades: problemas y perspectivas, I, Madrid, 189222.

Vera, M. (2008), Excavación Arqueológica Pre- ventiva en el inmueble de la calle Goles $n^{\circ} 19$ (Sevilla), Documento interno de la Delegación Provincial en Sevilla de la Consejería de Cultura de la Junta de Andalucía.

Viguera, Mํ‥ (1997), "Historiografía”, El retroceso territorial de al-Andalus. Almorávides y almohades siglos XI al XIII, Historia de España Menéndez Pidal, VIII-II, Madrid, 1-37.

(1998), "La ciudad almohade de Sevilla", VIII Centenario de la Giralda (1198-1998), Córdoba, 15-30.

(1999), "Los almohades en Sevilla: 1147-1248”, Sevilla almohade, Madrid, 19-23.

Villa, C., Rodríguez, A. y Fernández, A. (2010), "Intervención arqueológica preventiva en el inmueble situado en la calle Goles $n^{\circ} 39$ de Sevilla", Anuario Arqueológico de Andalucía/2005, Sevilla, 3249-3259.

Viñuales, O. (1999), Intervención arqueológica en calle Valdés Leal $n^{\circ}$ 23. Sevilla, Documento interno de la Delegación Provincial en Sevilla de la Consejería de Cultura de la Junta de Andalucía. 
